\title{
Review
}

\section{Antiviral Drugs in Influenza}

\author{
Magdalena Świerczyńska ${ }^{1}\left(\mathbb{D}\right.$, Dagmara M. Mirowska-Guzel ${ }^{1, *} *$ and Edyta Pindelska ${ }^{2}$ (D) \\ 1 Centre for Preclinical Research and Technology CePT, Department of Experimental and Clinical \\ Pharmacology, Medical University of Warsaw, Banacha 1B, 02-097 Warsaw, Poland; \\ lek.wet.magdaswierczynska@gmail.com \\ 2 Department of Analytical Chemistry and Biomaterials, Faculty of Pharmacy, Medical University of Warsaw, \\ Banacha 1B, 02-093 Warsaw, Poland; edyta.pindelska@wum.edu.pl \\ * Correspondence: dagmara.mirowska-guzel@wum.edu.pl; Tel.: +48-22-116-6160; Fax: +48-22-116-6202
}

Citation: Świerczyńska, M.; Mirowska-Guzel, D.M.; Pindelska, E. Antiviral Drugs in Influenza. Int. J. Environ. Res. Public Health 2022, 19, 3018. https://doi.org/10.3390/ ijerph19053018

Academic Editor: Paul B. Tchounwou

Received: 30 December 2021

Accepted: 25 February 2022

Published: 4 March 2022

Publisher's Note: MDPI stays neutral with regard to jurisdictional claims in published maps and institutional affiliations.

Copyright: () 2022 by the authors. Licensee MDPI, Basel, Switzerland. This article is an open access article distributed under the terms and conditions of the Creative Commons Attribution (CC BY) license (https:// creativecommons.org/licenses/by/ $4.0 /)$.

\begin{abstract}
Flu is a serious health, medical, and economic problem, but no therapy is yet available that has satisfactory results and reduces the occurrence of these problems. Nearly 20 years after the registration of the previous therapy, baloxavir marboxil, a drug with a new mechanism of action, recently appeared on the market. This is a promising step in the fight against the influenza virus. This article presents the possibilities of using all available antiviral drugs specific for influenza A and B. We compare all currently recommended anti-influenza medications, considering their mechanisms of action, administration, indications, target groups, effectiveness, and safety profiles. We demonstrate that baloxavir marboxil presents a similar safety and efficacy profile to those of drugs already used in the treatment of influenza. Further research on combination therapy is highly recommended and may have promising results.
\end{abstract}

Keywords: influenza treatment; amantadine; neuraminidase inhibitors; zanamivir; oseltamivir; peramivir; laninamivir; baloxavir marboxil

\section{Introduction}

Influenza is a contagious disease that affects populations on a global scale. In humans, the etiological factor causing infections is influenza A or B virus and, to a small extent, influenza $C$ virus. However, the greatest threat to humans is the type $A$ virus due to its strong tendency toward antigenic variation and its pandemic potential. The disease can run its course in various ways, from asymptomatic infections or a mild infection of the upper respiratory tract to severe disease with high fever, chills, muscle pain, pneumonia, and even death [1]. According to the World Health Organization (WHO), the annual global influenza attack rate ranges from $20 \%$ to $30 \%$ of the child population and up to $10 \%$ of the adult population [2]. The number of deaths due to influenza is approximately 290,000-650,000 annually [3]. These factors constitute a global health, medical, and economic burden [4-6].

To reduce the influenza problem, research is constantly being carried out to monitor the directions of antigenic changes in the influenza virus. There is also ongoing work on new antiviral drugs and vaccines, the compositions of which are reconfigured every year [1]. Nevertheless, treating influenza remains a challenge, and the selection of appropriate drugs and the potential of combination therapy require a thorough knowledge of medicines available on the market and consideration of associated factors, such as the patient's age, general health, and increased risk of possible complications. There are currently three registered drug types that specifically target the influenza virus: M2 proton channel antagonists (amantadine), neuraminidase inhibitors (NAIs; zanamivir, oseltamivir, peramivir, and laninamivir), and polymerase acidic endonuclease inhibitor (baloxavir marboxil), which is new in terms of its mechanism of action [7]. 
In this review, we aim to illustrate the extent to which a new drug can affect the success, effectiveness, and safety of influenza therapy. The detailed presentation and comparison of all flu-specific antiviral drugs on the market will help answer these questions.

\section{Influenza Virus}

\subsection{Structure of Influenza Virus}

Influenza virus belongs to the Orthomyxoviridae family and has a spherical or filamentous shape, a viral envelope, and a segmented, negative-sense, single-stranded RNA genome [8-10]. There are two glycoproteins on the surface of the virus that control its ability to cause disease: hemagglutinin (HA) and neuraminidase (NA) [9-13]. These two proteins are antigens and define the specific influenza strain [14]. Another transmembrane protein is M2, which forms the ion channel. Under the glycoprotein envelope of the virus is a matrix made up of M1 protein, which shapes the virion and encloses its core [9-13]. Inside the matrix is the viral genome in the form of segmented RNA and non-structural nuclear export proteins (NEPs). Single-stranded viral RNA (vRNA) coated with nucleoprotein (NP) exists in a complex with RNA polymerase. RNA polymerase consists of three subunits (PB1, PB2, and PA) and is necessary for the transcription of viral genetic material during the replication of influenza virus [10].

\subsection{Influenza Virus Life Cycle}

After entering the respiratory tract, the influenza virus must travel through the thick layer of mucus covering the epithelium of the respiratory system. The main component of the mucus is oligosaccharides, which contain sialic acid. Viral NA hydrolyzes the $\alpha$ glycosidic bond in the sialic acid molecules, relaxing the mucus and allowing the virions to bind to respiratory epithelial receptors [15]. The entry of the virus into the host cell by endocytosis is possible due to HA, which allows adhesion to the respiratory epithelial cell, as shown in Figure 1. This process involves the binding of HA to the sialic acid residues of surface receptors on the host cell. This leads to viral fusion and penetration of viral RNA into the cell interior $[9,12,16]$. After entering the host cell, the viral genetic material is released from the virion. This is possible due to the opening of M2 ion channels and acidification of the virus core. This acidic environment in the virion releases the viral RNA complex from the protein matrix into the host cell's cytoplasm. Influenza vRNA is negative-sense RNA, which means that it must first be transcribed to positive-sense RNA before it can be used as a template for the production of vRNA. For this purpose, viral ribonucleoproteins (vRNPs) translocate to the interior of the host cell nucleus from the cytoplasm. Host mRNA and the RNA polymerase complex play key roles in the replication of influenza vRNA. The RNA polymerase complex consists of three PA subunits, PB1, and PB2, which are involved in transcription as follows. Due to the PA subunits, the cap of host mRNA is hydrolyzed and detached, and the primers for vRNA transcription are created. Next, the PB2 subunit binds the $5^{\prime}$ end of host mRNA, which allows the initiation of transcription of viral mRNA using the vRNA template. The PB1 subunit of the polymerase is responsible for the synthesis of mRNA strands $[10,15,17]$. The viral mRNA is exported to the cytoplasm of the cell, where translation of the viral proteins HA, NA, M1, and M2 takes place. At the same time, new copies of vRNA are transcribed in the host cell nucleus. The increased amount of synthesized M1 protein leads to the enhancement of nuclear vRNA export with the participation of NEPs, NP exporting proteins, and host proteins. In addition, by means of the COPI coat protein complex, HA, NA, and M2 proteins are transported to the apical part of the host cell membrane. M1 together with vRNA is transported to the cytoplasm. The M1 protein and vRNPs accumulate on the inner side of the membrane of the apical part of the host cell. Next, due to the interaction with the M1 protein, segments of vRNA are packed into virions [15]. A budding zone of the cell membrane is created as a result of the accumulation of proteins in this zone of the cell. The M2 protein is involved in the shape formation and detachment of the bubble. Newly replicated viruses are released due to NA, a tetrameric protein that has enzymatic activity 
and catalyzes the breaking of the alpha-ketosidic bond between sialic acid and adjacent sugar residues $[12,15,18,19]$. Without the participation of NA, only one round of replication would take place, significantly reducing, or even inhibiting, the infection and preventing the development of disease [14].

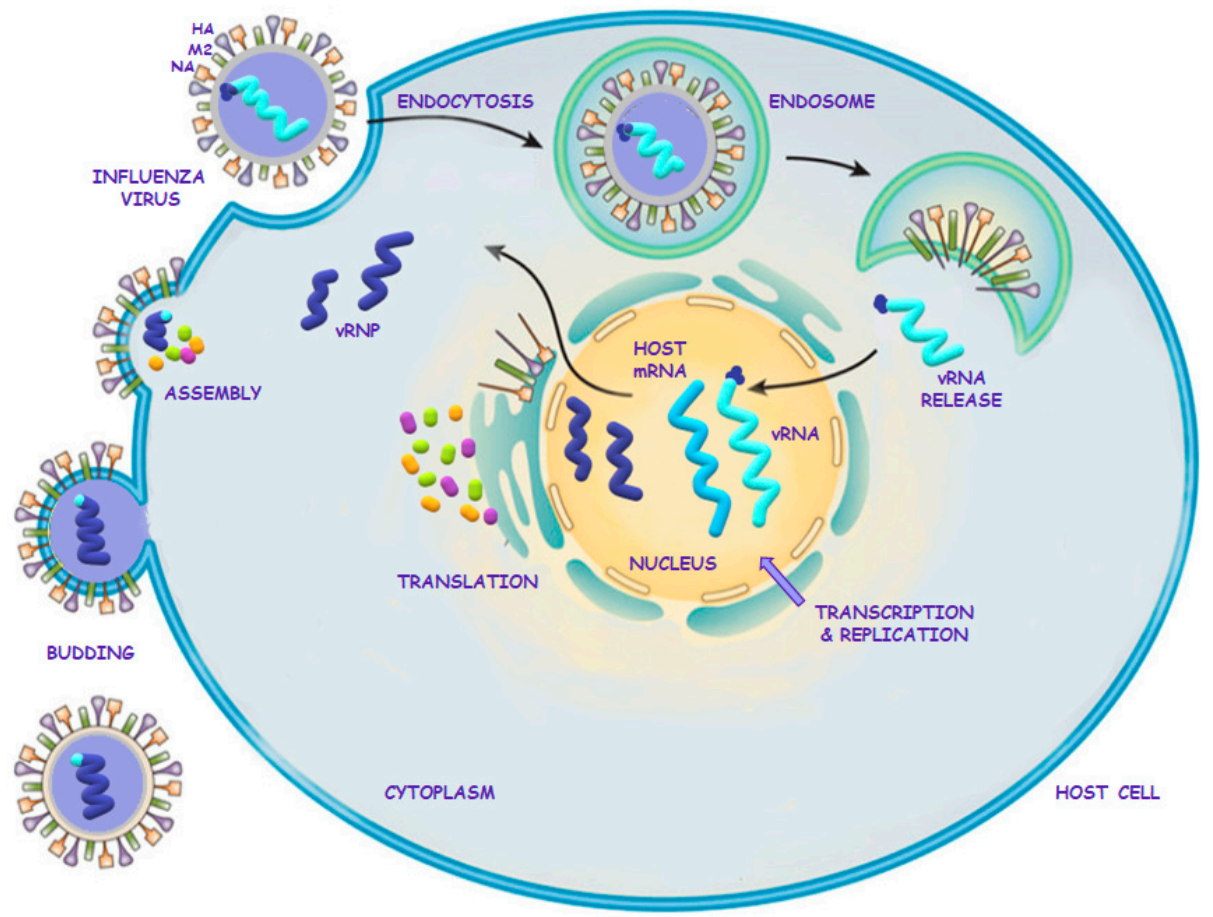

Figure 1. Life cycle of influenza A virus.

\section{Drugs Used for Influenza Treatment and Prophylaxis}

\subsection{Amantadine}

Amantadine was the first antiviral drug used in the treatment of influenza. Due to its mechanism of action, it can only be used against influenza A [20,21]. This drug inhibits viral replication by blocking the A/M2 proton channel specific to influenza A virus. However, naturally occurring point mutations in the transmembrane domain, which occur relatively quickly, have resulted in new amantadine-resistant strains of influenza A [22,23].

Amantadine has a dose-dependent effect and two active forms: amantadine hydrochloride for oral use and amantadine sulfate for oral and intravenous use [24]. The first is used as antiviral treatment. In general, amantadine is well tolerated, but due to the risk of impaired excretion in the case of renal failure, it is recommended to start treatment with the lowest doses and doses adequate for creatinine clearance [25]. The effectiveness of amantadine antiviral treatment is estimated to be a $50 \%$ reduction in the duration of symptoms if therapy is started in the first $48 \mathrm{~h}$ of infection with amantadine-sensitive influenza A virus [21,26]. Due to increased global resistance, amantadine has not been recommended for the treatment of influenza since $2006[8,27,28]$. However, it is still an area of interest and has other registered indications [29,30].

Currently, amantadine is mainly used in neurodegenerative diseases, such as Parkinson's disease [31], therapy after traumatic brain injury [32,33], and multiple sclerosis [20,34]. Recently, due to the SARS-CoV-2 pandemic and the lack of specific treatment in this direction, attempts have been made to use amantadine in the fight against this deadly virus. It was noted that people with neurological diseases chronically treated with amantadine experienced asymptomatic SARS-CoV-2 infection [35]. A preliminary therapeutic effect of amantadine in patients with severe disease has also been demonstrated [36]. However, documented data remain insufficient to draw clear conclusions, and amantadine is not recommended in COVID-19 therapy. 


\subsection{Neuraminidase Inhibitors (NAIs) \\ 3.2.1. Group Presentation}

NAIs are the largest group of drugs and are currently the most commonly prescribed and used drugs in the treatment of human influenza [37-39]. Their mechanism of action, consisting of the inhibition of viral replication in vitro and in vivo, was first demonstrated by von Itzstein et al. in 1993 based on the example of zanamivir [40]. Zanamivir entered clinical trials 1 year later [41] and was first approved by the Food and Drug Administration (FDA) for the treatment of influenza A and B infections on 26 July 1999 as a powder formulation for oral inhalation [1]. In 2006, it was approved for the prevention of influenza A and B [37]. Another NAI described by Kim et al. in 1997 was oseltamivir [42], which was first registered for medical use in 1999 in the US for oral use as Tamiflu ${ }^{\circledR}$ (Roche) [11]. The NAIs currently available for general use include zanamivir, oseltamivir, peramivir, and laninamivir $[11,18,43]$. All of them are effective against most strains of influenza A and B [18] and, unlike amantadine, are associated with low toxicity and are significantly less likely to promote the development of drug resistance [14].

NAIs should be administered within the first $48 \mathrm{~h}$ of symptom onset. This is related to the peak of viral replication in the respiratory tract, which occurs between 24 and $72 \mathrm{~h}$ after infection with influenza virus and is a key period to inhibit this process [14]. Although the best clinical benefit is obtained after using any NAIs within the first 2 days after the onset of symptoms, some studies have demonstrated a good clinical response, even up to 5 days after symptom onset [44-46]. Numerous studies have shown that the use of NAIs shortens the length of treatment and hospitalization in seriously ill patients in intensive care units (ICUs) and reduces the risk of death [37,47-52]. Currently, for patients with a suspected or confirmed influenza infection, it is recommended to start treatment with drugs from this class as soon as possible [49]. NAIs are also available for prophylaxis, and their use is especially recommended in people suffering from high-risk flu during influenza season. However, such use, though important and necessary, is only a support for vaccination, which remains the main form of prevention against influenza $[37,47,53]$.

Despite the significant efficiency of all NAIs, there is a constant need to improve and synthesize new variants due to the rapid, spontaneous, and uncontrolled variability in the influenza virus and the emerging drug resistance of some new strains $[47,54]$.

\subsubsection{Mode of Action}

NA is an exosialidase composed of a polypeptide chain containing 470 amino acid residues. The structure of the protein consists of the head, stalk, transmembrane domain, and cytoplasmic domain. On the tetrameric head are active sites that are essential for the hydrolysis process [55]. Each of the four protein monomers is anchored to a common point in the viral envelope. All four have a catalytic site with a linkage of sialic acid residues located in a deep, negatively charged pocket $[11,16]$. It is a calcium-binding domain made of oxygens from the rest of the main chain and the side chain. In addition, the active sites responsible for the catalytic function of the enzyme contain acid residues that are strictly conserved in influenza A and B viruses: Arg118, Arg152, Arg224, Arg292, Asp151, Glu276, Arg371, Tyr406, and the Asn146 glycosylation site in complex with zanamivir (Figure 2). The latter is distinguished by the presence of o- $4 \mathrm{~N}$-acetylgalactosamine sulfate. The hydrolytic activity of A consists of the formation of an oxocarbonate ion at the C2Neu5AC atom of the substrate. The introduction of the $\mathrm{C} 2 \mathrm{Neu} 5 \mathrm{AC}$ residue to the active site leads to strong ionic interactions between the substrate carboxylate and arginine guanidine groups, which then leads to a change in the conformation of Neu5Ac and cleavage of the glycosidic bond [55]. 


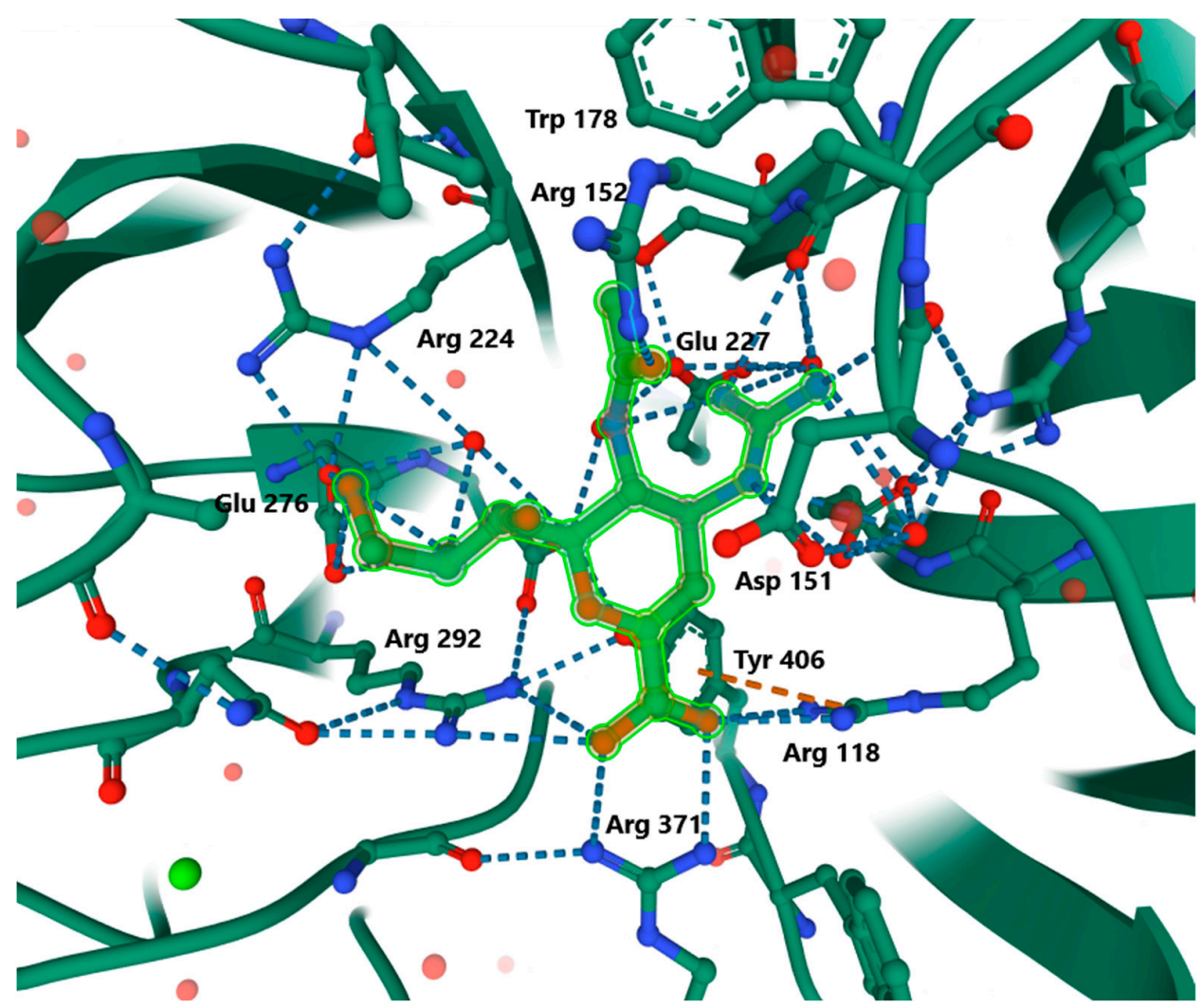

Figure 2. Influenza virus neuraminidase complexed with zanamivir.

Numerous viral mutations are associated with amino acid changes in the NA structure, but the sequences that build the active site of the cleft remain highly conserved. This fact was used in the design of antiviral drugs by using the conserved active site as their target $[16,56]$.

Analogs of 2,3-dehydro-2-deoxy-N-acetylneuraminic acid (DANA) with a $\mathrm{C} 4-\mathrm{OH}$ substitution and a 4-guanidino group mimic the transient state of the hydrolysis reaction. The interaction is the formation of a strong hydrogen bond between the carboxylic acid of the ligand and the residues Arg118, Arg292, and Arg371 in NA. Moreover, a specific hydrophobic contact occurs between the methyl group and two residues, Trp178 and Trp222 [55]. Due to this binding to the amino acid residues, NAIs block the active site of the enzyme via the most energetically advantageous interaction $[9,11,14,16,37,57]$.

The first NAI that was developed was zanamivir. The structure of its molecule is based on DANA (as shown in Table 1) and a positively charged guanidino group, which binds to the active site of NA in a highly conservative manner, causing its inhibition [11]. Oseltamivir was also designed based on a modification of the DANA structure. However, unlike zanamivir, it has a cyclohexene ring, $\mathrm{C} 4$ amino group, and lipid side chain [11,12,14]. This allows oral administration of oseltamivir, which, as a phosphate prodrug, undergoes hepatic metabolism by carboxylesterases to its active form, oseltamivir carboxylate (OC) $[12,16,58,59]$. Peramivir's structure and mechanism of action differ slightly from those of other NAIs. Based on DANA, it has a cyclopentane ring, a guanidino group, and a hydrophobic side chain [11,12]. As a result, it establishes multiple interactions with the NA catalytic site, which makes it active against some strains of influenza A and B viruses resistant to older drugs of this class [37]. Peramivir is administered as an intravenous infusion. The only long-acting NAI is laninamivir, the synthesis of which is based on zanamivir with a 7-OCH3 substitution. It is administered in a single dose by oral inhalation [11], and its main advantage is activity against some oseltamivir-resistant strains of influenza virus [37]. 
Table 1. Antiviral drugs recommended for use against influenza viruses.

\begin{tabular}{|c|c|c|c|}
\hline Drug Class & Active Substance & CID & Trade Name \\
\hline NAI & & 60855 & $\begin{array}{c}\text { Relenza }{ }^{\circledR} \text { registered in } \\
\text { EU, USA and Asi- } \\
\text { aDectova }{ }^{\circledR} \text { registered } \\
\text { in EU }\end{array}$ \\
\hline NAI & & 65028 & $\begin{array}{c}\text { Tamiflu®registered in } \\
\text { EU, USA and Asia }\end{array}$ \\
\hline NAI & & 154234 & $\begin{array}{c}\text { Rapivap }{ }^{R} \text { registered } \\
\text { in USA and Asia }\end{array}$ \\
\hline NAI & & 502272 & $\begin{array}{c}\text { Inavir }{ }^{\circledR} \text { registered in } \\
\text { Asia }\end{array}$ \\
\hline CENI & & 124081896 & $\begin{array}{c}\text { Xofluza }{ }^{\circledR r} \text { registered in } \\
\text { EU, USA and Asia }\end{array}$ \\
\hline & baloxavir marboxil & & \\
\hline
\end{tabular}

Regardless of the structure of the molecule, all NAIs mimic the sialic acid transition state by binding specifically to the active site of NA, leading to blockage of its enzymatic function $[9,14]$. As a consequence, viral replication stops at the stage of viral envelope formation, preventing the release of progeny virions from host cells and their subsequent spread $[9,11,14,37,57]$.

\subsubsection{Zanamivir}

Drug Presentation

Currently, zanamivir is approved for use under the two trade names Relenza ${ }^{\circledR}$ (GlaxoSmithKline, GSK) and Dectova ${ }^{\circledR}$ (GSK) [60-63]. Relenza is available in 70 countries around the world as an anti-influenza A and B treatment and preventative [56]. Dectova ${ }^{\circledR}$ is a new preparation of zanamivir as a solution for infusion and authorized throughout the European Union [57]. 
Pharmacokinetics of Zanamivir for Oral Inhalation

Zanamivir is administered as a powder for oral inhalation (Relenza ${ }^{\circledR}$, GSK). The main excipient is lactose monohydrate, which contains milk proteins $[61,64]$. Zanamivir is mixed with lactose in a proportion of 1:4, which is $5 \mathrm{mg}$ of active substance per $20 \mathrm{mg}$ of excipient $[12,64]$. Due to its large molecule size $(>40 \mu \mathrm{m})$, lactose causes the main part (about 78\%) of the drug to deposit in the mouth and throat, which is the first location of infection. The rest of the inhalation, $\sim 13-15 \%$, is deposited in the tracheobronchial tree and the lungs [12]. The drug concentration in the respiratory tract has been estimated to be 1000 times higher than the 50\% inhibitory concentration (IC50) for NA [14]. Absolute bioavailability is very low following oral administration (1-5\%). Following oral inhalation, bioavailability is $4 \%$ to $17 \%$. The volume of distribution approximates that of extracellular water. Zanamivir plasma protein binding is limited and estimated to be $<10 \%$. Zanamivir is not metabolized; the serum half-life ranges from 2.5 to $5.1 \mathrm{~h}$, and it is excreted unchanged in the urine by the kidney, with the excretion of a single dose completed within $24 \mathrm{~h}$ [65].

\section{Treatment and Prophylaxis with Zanamivir for Oral Inhalation}

The active component of Relenza ${ }^{\circledR}$ is zanamivir; its pharmaceutical form is white to off-white powder contained in a disc blister, pre-dispensed with $5 \mathrm{mg}$ of zanamivir per dose and administered using the Diskhaler, a specially designed breath-activated plastic device $[61,64]$. Each inhalation that is deposited in the mouth delivers $4.0 \mathrm{mg}$ of zanamivir to the respiratory tract.

Zanamivir for inhalation is licensed for treatment of influenza A and B in patients with typical symptoms during periods in which influenza virus is circulating in the community. The drug is authorized for treatment in adults and children ( $\geq 5$ years) in most countries, including the European Union and Australia, and in patients aged 7 years and older in the United States and Canada $[61,64,66]$. The recommended dosage for treatment of influenza is two inhalations of $5 \mathrm{mg}$ each twice daily (approximately $12 \mathrm{~h}$ apart) for 5 days. Treatment should be started as soon as possible, no later than $36 \mathrm{~h}$ after the onset of symptoms in children and $48 \mathrm{~h}$ after the onset of symptoms in adults. Two doses should be taken on the first day with at least $2 \mathrm{~h}$ between doses $[61,64]$.

For seasonal prophylaxis against influenza, zanamivir for oral inhalation is approved in most countries for adults and children over 5 years of age and in Canada for adults and children aged 7 years and older. The recommended dose is $10 \mathrm{mg}$ of zanamivir once daily for 28 days [61,64]. It is also approved for post-exposure prophylaxis against influenza A and B in an individual exposed to clinically symptomatic household members. In this case, it is recommended to use the drug up to $36 \mathrm{~h}$ after contact with the patient at a dose of $10 \mathrm{mg}$ once daily for 10 days (approximately $24 \mathrm{~h}$ apart) [61,64].

The drug is also approved for prophylaxis in the event of an epidemic or pandemic of influenza A and B, such as when there is a mismatch between the strains contained in the vaccines and those circulating in the general population. However, zanamivir is not a substitute for influenza immunization, and its prophylactic use should always be determined on a case-by-case basis.

A contraindication to the use of zanamivir for oral inhalation is an allergy to milk protein. In addition, patients with glucose-galactose malabsorption, hereditary galactose intolerance, and Lapp lactase deficiency should not use this medicine. There have been reports of unsuccessful attempts to administer Relenza ${ }^{\circledR}$ by nebulization or mechanical ventilation due to the drug's lactose content. Consequently, it obstructs the action of the equipment $[61,64]$. Due to very rare reports of bronchospasm and declining respiratory function after drug administration, its usage in patients with asthma and chronic obstructive pulmonary disease (COPD) requires great care. In these special cases, the patient should be advised of the risk of bronchospasm and the need for a fast-acting bronchodilator. Due to limited data, it is not possible to definitively determine the efficacy and safety of zanamivir for oral inhalation in patients with asthma, chronic respiratory disease, immune 
deficiencies, or unstable chronic illnesses; in pregnant and lactating women; in elderly patients over 65 years of age; and in the prevention of influenza in nursing homes $[61,64,67]$.

Zanamivir for oral inhalation has been associated with the potential for adverse effects (AEs) and complications. Some of the more common reactions that can occur with the use of zanamivir inhalation powder include skin reactions, such as rash. Studies have shown that such reactions may occur in $1 \%$ to $10 \%$ of patients. Uncommon AEs that have been reported include disordered respiratory function, bronchospasm, throat tightness or constriction, vasovagal-like reactions, and allergic-type reactions, including oropharyngeal edema and urticaria. The frequency of this type of reaction is estimated to be $0.1 \%$ to $1 \%$. Rare AEs have been observed in less than $0.01 \%$ of patients and include anaphylactic reaction, facial edema, toxic epidermal necrolysis, erythema multiforme, and Stevens-Johnson syndrome [64] (Table 2). In addition, there are post-marketing reports of incidents of psychiatric and nervous system disorders in influenza patients treated with zanamivir for oral inhalation. Seizures, delirium, hallucination, abnormal behavior, and depressed level of consciousness have been described [62,64].

Table 2. Summary of frequency of serious or minor adverse effects associated with the administration of NAIs. Data from $[9,12,14,16,43,59,62,64-76]$.

\begin{tabular}{|c|c|c|}
\hline Drug & Frequency & Adverse Effects \\
\hline \multirow{4}{*}{ Zanamivir for oral inhalation } & $1 \%$ to $10 \%$ & Skin reaction, such as rash \\
\hline & $0.1 \%$ to $1 \%$ & $\begin{array}{l}\text { Disordered respiratory function, } \\
\text { bronchospasm, throat tightness or } \\
\text { constriction, vasovagal-like } \\
\text { reactions, and allergic-type } \\
\text { reactions, including oropharyngeal } \\
\text { edema and urticaria. }\end{array}$ \\
\hline & $<0.01 \%$ & $\begin{array}{c}\text { Anaphylactic reaction, facial edema, } \\
\text { toxic epidermal necrolysis, } \\
\text { erythema multiforme, and } \\
\text { Stevens-Johnson syndrome }\end{array}$ \\
\hline & Underestimated & $\begin{array}{l}\text { Neuropsychiatric adverse effects } \\
\text { (NPAEs), seizures, delirium, } \\
\text { hallucination, abnormal behavior, } \\
\text { and depressed level } \\
\text { of consciousness }\end{array}$ \\
\hline \multirow{3}{*}{ Intravenous zanamivir } & $1 \%$ to $10 \%$ & $\begin{array}{l}\text { Diarrhea, rash, hepatocellular } \\
\text { injury, increased levels of } \\
\text { transaminases (ALT and AST), } \\
\text { neutropenia, and renal failure }\end{array}$ \\
\hline & $0.1 \%$ to $10 \%$ & $\begin{array}{l}\text { Urticaria and increased } \\
\text { alkaline phosphatase }\end{array}$ \\
\hline & Underestimated & $\begin{array}{l}\text { Anaphylactic reaction, facial and } \\
\text { oropharyngeal edema, NPAEs, } \\
\text { renal impairment, paralytic ileus, } \\
\text { and hypotension }\end{array}$ \\
\hline
\end{tabular}


Table 2. Cont.

\begin{tabular}{|c|c|c|}
\hline Drug & Frequency & Adverse Effects \\
\hline \multirow{4}{*}{ Oseltamivir } & $>10 \%$ & Headache and nausea \\
\hline & $1 \%$ to $10 \%$ & $\begin{array}{l}\text { Vomiting, bronchitis, sore, throat, } \\
\text { nasopharyngitis, sinusitis, pain, } \\
\text { and dizziness }\end{array}$ \\
\hline & $0.1 \%$ to $1 \%$ & $\begin{array}{l}\text { Hypersensitivity reaction, rash, } \\
\text { urticaria, dermatitis, cardiac } \\
\text { arrhythmia, and convulsions }\end{array}$ \\
\hline & $00.1 \%$ to $0.1 \%$ & $\begin{array}{l}\text { Thrombocytopenia, anaphylactic } \\
\text { reactions, toxic epidermal } \\
\text { necrolysis, hepatic failure, hepatitis, } \\
\text { evaluated liver enzymes, } \\
\text { gastrointestinal bleeding, visual } \\
\text { disturbances, and NPAEs }\end{array}$ \\
\hline \multirow[b]{3}{*}{ Peramivir } & $>10 \%$ & Diarrhea \\
\hline & $1 \%$ to $10 \%$ & $\begin{array}{c}\text { Neutropenia, nausea, vomiting, } \\
\text { injection site rash, and increased } \\
\text { AST and ALT }\end{array}$ \\
\hline & Underestimated & $\begin{array}{l}\text { Insomnia, fever, proteinuria, } \\
\text { tympanic membrane erythema, } \\
\text { anaphylactic reactions, severe } \\
\text { dermatological reactions such as } \\
\text { Stevens-Johnson syndrome and } \\
\text { exfoliative dermatitis, and NPAEs }\end{array}$ \\
\hline \multirow[b]{2}{*}{ Laninamivir } & $1 \%$ to $10 \%$ & Cough, diarrhea, and headache \\
\hline & $0.1 \%$ to $1 \%$ & $\begin{array}{l}\text { Gastritis, abnormal behavior, and } \\
\text { nervous system disorders }\end{array}$ \\
\hline
\end{tabular}

Pharmacokinetics of Intravenous Zanamivir

After intravenous administration of Dectova ${ }^{\circledR}$, zanamivir binds plasma proteins to a very low degree $(<10 \%)$, and the central volume of distribution is approximately $16 \mathrm{~L}$, which approximates the volume of extracellular water. The drug does not accumulate in serum, and proportionality has been demonstrated between its maximum concentration (Cmax) and the area under the curve (AUC). Zanamivir is not significantly metabolized and is eliminated unchanged in the urine by glomerular filtration, with a half-life of approximately $2-3 \mathrm{~h}$ in adults with normal renal function after repeated intravenous doses of $600 \mathrm{mg}$ twice daily [77-80].

Treatment with Intravenous Zanamivir

Dectova ${ }^{\circledR}$ is a zanamivir solution for infusion designed to treat seriously ill, hospitalized patients with life-threatening infections with influenza A or B virus $[43,65,81]$. This medicine was approved by the European Medicines Agency (EMA) in 2019 and has the status of a drug under additional monitoring, which means that Dectova ${ }^{\circledR}$ is subject to constant reporting on its effectiveness and safety, as well as the analysis of its benefit-risk profile in everyday medical practice [63].

Intravenous zanamivir is registered for treatment in patients with known or suspected influenza virus infection resistant to other antiviral drugs and in patients whose medical condition does not allow the use of medications suitable for oral administration or inhalation, such as patients with sepsis, intestinal obstruction, or malabsorption $[43,65,78,82-85]$. Zanamivir is effective in inhibiting the replication of most oseltamivir-resistant influenza viruses, including strains with one of the most common H275Y mutations in N1 viruses $[66,78,86]$. 
Dectova ${ }^{\circledR}$ is available on the market in $1 \%$ solutions of zanamivir (as hydrate); each vial of clear, colorless intravenous solution contains $200 \mathrm{mg}$ of zanamivir in $20 \mathrm{~mL}$ dilution. An excipient with known effects is sodium (70.8 $\mathrm{mg}$ per vial) $[43,65]$. Intravenous zanamivir is licensed for adults, adolescents, and children over 6 months old. The recommended dose is $600 \mathrm{mg}$ twice daily for 5-10 days, and treatment should be started in the first 6 days after the onset of influenza symptoms. However, weight-dependent treatment is recommended in infants, children, and adolescents weighing $\geq 50 \mathrm{~kg}$ as follows: children up to 6 years old, $14 \mathrm{mg}$ per $\mathrm{kg}$ body weight twice daily for 5-10 days; children $\geq 6$ years to $<18$ years old, $12 \mathrm{mg}$ per $\mathrm{kg}$ body weight twice daily for 5-10 days. In patients with renal impairment, the dose should be individually adjusted according to the degree of renal failure and creatinine clearance $[43,65,78]$.

Phase 2 and 3 clinical trials reported some adverse effects related to the drug (Table 2). The most common were gastrointestinal events, including diarrhea, rash, hepatic reactions such as hepatocellular injury, and increased levels of transaminases (ALT and AST). In children, neutropenia and renal failure were reported. Studies have shown that the frequency of common AEs during treatment with intravenous zanamivir is $1 \%$ to $10 \%$. Uncommon AEs include urticaria and increased alkaline phosphatase, affecting up to 1 in 100 patients. The possibility of anaphylactic reaction, facial and oropharyngeal edema, neuropsychiatric reactions (such as abnormal behavior, delirium, and depressed level of consciousness), renal impairment, paralytic ileus, and cardiovascular events, including hypotension, have also been noted, but due to limited data, the frequency of occurrence could not be determined $[43,65,66]$.

\subsubsection{Oseltamivir}

Drug Presentation

Oseltamivir is an orally administered antiviral drug approved under the original trade name Tamiflu ${ }^{\circledR}$ (Roche). It is the most commonly prescribed and utilized NAI for the treatment of influenza A and B infections $[49,87,88]$.

\section{Pharmacokinetics}

Oseltamivir is administered orally as the prodrug oseltamivir phosphate salt and rapidly absorbed by the gastrointestinal tract. Hepatic esterases extensively hydrolyze it into the active form of oseltamivir carboxylate (OC) $[9,16,18,88,89]$. At least $80 \%$ of an oral dose reaches the systemic circulation as the active metabolite $[9,16,89]$. Absolute bioavailability is proportional to the dose and is similar in severely ill patients and those with mild symptoms $[90,91]$. It is unaffected by co-administration with food $[9,12,14]$. The mean volume of distribution is approximately $25.6 \mathrm{~L}$ in humans, a volume that is roughly equivalent to the extracellular body fluid. The binding of the prodrug is $42 \%$, and only approximately $3 \%$ of the active form of OC binds to human plasma protein [67]. After oral administration at a dose of $150 \mathrm{mg}$, OC has an AUC of $6834 \mu \mathrm{g} / \mathrm{L} / \mathrm{h}$, Tmax of $2.88 \mathrm{~h}$, and Cmax of $2091 \mu \mathrm{g} / \mathrm{L}$ [9]. The main route of oseltamivir elimination is generally via the kidneys (>99\%), and the drug is excreted in the urine as OC $[9,16]$ and requires dose reduction in patients with renal failure $[49,58,88]$. Plasma concentrations of oseltamivir decline with a half-life of $6.7-8.2 \mathrm{~h}$ after oral administration. Renal clearance of the drug, $18.8 \mathrm{~L} / \mathrm{h}$, exceeds the glomerular filtration rate of $6.67 \mathrm{~L} / \mathrm{h}$, indicating that tubular secretion occurs in addition to glomerular filtration $[9,67]$.

\section{Treatment and Prophylaxis with Oral Oseltamivir}

Tamiflu $^{\circledR}$ is available in the pharmaceutical form as $30 \mathrm{mg}, 45 \mathrm{mg}$, or $75 \mathrm{mg}$ hard capsules and $6 \mathrm{mg} / \mathrm{mL}$ powder for oral suspension $[67,68]$. The EMA approved oseltamivir for treatment in adults, adolescents, and children, including full-term neonates, who show symptoms typical of influenza infection during periods of increased viral activity in the environment $[49,67,68]$. In the United States, the drug is approved for the treatment of uncomplicated influenza A and B in patients older than 2 weeks of age $[58,59,68]$. 
Similar to zanamivir, treatment with oseltamivir should be started $48 \mathrm{~h}$ after the onset of symptoms [67-69]. However, in special cases in hospitalized, seriously ill patients and in those at high risk of complications, it is recommended to initiate treatment with oseltamivir regardless of the time of onset. Such recommendations are based on studies that have shown a beneficial therapeutic effect of oseltamivir in hospitalized patients with influenza who started treatment 4 and 5 days after the onset of symptoms [59]. The registration of oseltamivir is also for prophylaxis. The EMA and FDA authorized the use of the drug in people older than 1 year of age in the case of contact with a person clinically diagnosed with influenza $[67,68]$. In a case of a global spread of the influenza virus, such as during a pandemic, when the vaccine does not provide the required protection, the EMA allows Tamiflu ${ }^{\circledR}$ prophylaxis for the whole population, including full-term infants [67]. However, regardless of the circumstances, special care should be taken to avoid using oseltamivir for prophylaxis in individuals who have been treated with this drug in the past due to the risk of new viral mutations [37]. In addition, the WHO indicates oseltamivir as the drug of choice for the treatment and prevention of influenza caused by virulent influenza strains, including influenza A (H1N1) [92].

Acute, subacute, and chronic toxicity studies have demonstrated a high margin of safety for oseltamivir and no oncogenic and mutagenic effects [93,94]. Overall, the drug is well tolerated, and the most common adverse effects are headache and digestive system disorders [12,59,67-69]. Nausea and vomiting have been observed most frequently on the first day of treatment after the first dose, usually lasting for up to 2 days and resolving spontaneously $[9,14]$. The frequency of such symptoms increases with increasing dose and is probably associated with local irritation of the gastric mucosa [9,12]. Taking oseltamivir with food does not affect its bioavailability and is recommended to reduce negative gastrointestinal symptoms $[9,12,14,16,70]$. Other reported side effects, though much less likely to occur, are very serious and include anaphylactic reactions, toxic epidermal necrolysis, cardiac arrhythmia, hepatic failure (including hepatitis), gastrointestinal bleeding [59,67-69], and also other equally serious but usually not life-threatening effects (e.g., dermatitis, rash, visual disturbances, and evaluated liver enzymes) [67,69]. Notably, neuropsychiatric adverse events (NPAEs) have been reported during oseltamivir treatment in patients with influenza [37,53,58,59,69,95]. Such events have been reported in Japan, where the drug is widespread and used for the early treatment of influenza and the prevention of epidemic influenza. Due to numerous reports of self-injury, abnormal behavior, and some fatalities in adolescents, Japan's Ministry of Health, Labor and Welfare (MHLW) issued a warning against the use of oseltamivir in March 2007. In response to this situation, the FDA analyzed data reports from Japan and the US regarding patients who experienced NPAEs from August 2005 to June 2006. Due to the lack of strong evidence, a strict relationship between the use of the drug and the occurrence of NPAEs cannot be concluded [96]. However, patients with influenza, especially children and adolescents treated with oseltamivir, should be closely monitored [96], and the expected symptoms include abnormal behavior, delirium, hallucination, self-injury, agitation, anxiety, delusions, and confusion [67,69].

To treat adults, oseltamivir is used at a dose of $75 \mathrm{mg}$ twice a day for 5 days $[16,37,67-69,88]$. The exceptions are patients on immunosuppression, for whom it is recommended to extend the treatment to 10 days $[67,69]$. According to data from pharmacological studies showing differences between children and adults, in children and adolescents younger than 13 years, the dose should be adjusted for weight and age group [58]. Furthermore, among patients with renal failure, the dose of oseltamivir should correlate with creatinine clearance, the degree of kidney dysfunction, and body weight [49,58,67-69]. Finally, obese adults, including those with a BMI $>40 \mathrm{~kg} / \mathrm{m}^{2}$, do not require an increased dose [49].

\section{Oseltamivir as an Over-the-Counter Drug}

As influenza is a serious health, economic, and epidemiological problem in the US, attempts were made to register oseltamivir as an over-the-counter drug in 2019. There would be many advantages of such a solution. General access to the drug could shorten 
the time from the first symptoms of the disease to treatment application, which seems to be a key factor in the effectiveness of therapy. This could significantly relieve the burden on health services and reduce the number of severely ill patients requiring hospitalization. On the other hand, there is concern about drug abuse that could lead to drug resistance. There are also some risks associated with diminished public interest in vaccine prophylaxis. Thus, balancing the benefits and losses is extremely important in the final decision to register oseltamivir as an over-the-counter medicine [40]. At the moment, such regulation has not entered into force, but this may change soon [97].

Several generics for Tamiflu ${ }^{\circledR}$ are currently available on the European market, including EMA-approved Ebilfumin. All of them require a prescription [95,98].

\subsubsection{Peramivir}

\section{Drug Presentation}

Peramivir was approved for use in Japan in 2010 under the trade name Rapiacta ${ }^{\circledR}$ (BioCryst Pharmaceuticals (BCP)) and the same year in South Korea as PeramiFlu ${ }^{\circledR}(B C P)$. Subsequently, the drug was approved in the United States in 2014 as Rapivab ${ }^{\circledR}$ (BCP) and in the EU in 2018 under the trade name Alpivab ${ }^{\circledR}$ (BCP) [71]. However, Alpivab ${ }^{\circledR}$ has been withdrawn from the EU market at the request of the manufacturer for commercial reasons [99].

\section{Pharmacokinetics}

The pharmacokinetic parameters following intravenous administration of peramivir at a dose of $800 \mathrm{mg}$ or $400 \mathrm{mg}$ twice daily exhibit a linear relationship between dose and exposure parameters (Cmax and AUC) [100]. Peramivir binds plasma proteins at a rate of $<30 \%$, and the central volume of distribution is approximately $12.56 \mathrm{~L}$. Peramivir is not significantly metabolized in humans. The major route of elimination of peramivir is via the kidney. In patients with normal renal function, peramivir intravenously administered as a single $600 \mathrm{mg}$ dose is eliminated with a half-life of approximately $20 \mathrm{~h}$. Renal clearance of unchanged peramivir accounts for approximately $90 \%$ of total clearance [101].

Treatment with Intravenous Peramivir

Rapivab $^{\circledR}$ is currently the only NAI approved by the FDA for the treatment of acute uncomplicated influenza and is provided in solution for intravenous infusion [71,97]. The uniqueness of this drug lies in the use of one parenteral dose [71-73]. The potential benefits of a single dose and intravenous administration make it possible to use this drug in patients with swallowing problems and in people with nausea and vomiting. In addition, the administration of only one dose significantly simplifies the treatment regimen and excludes the possibility of the patient skipping a dose of the drug [72].

Intravenous peramivir is approved for the treatment of acute uncomplicated influenza in adults and children over 2 years of age [94]. The recommended period from the onset of symptoms to initiation of treatment is $48 \mathrm{~h}$, the same as for other NAIs [73,94], but there are some reports of benefits from later peramivir use [71]. The drug is available as a colorless solution of $1 \%$ peramivir ( $200 \mathrm{mg}$ in $20 \mathrm{~mL}$ ). The intravenous peramivir dose is $600 \mathrm{mg}$ once in adults and adolescents and $12 \mathrm{mg} / \mathrm{kg}$ of body weight in children from 2 to 12 years of age [94]. Patients with renal impairment require adjustment of the dose to the level of creatinine clearance. Depending on the degree of glomerular filtration disorder, the dose does not change or amounts to one-third or one-sixth the standard dose [72,73].

Studies are being conducted on the effectiveness of peramivir treatment in seriously ill patients. It seems necessary to modify the dose and increase the number of doses in this group of patients. However, it requires further research [72,73].

Peramivir is generally well tolerated, and the most common adverse effects in adults are neutropenia and diarrhea (Table 2). Other AEs, though less common in this patient group, are constipation, insomnia, increased AST, and hypertension [71-73]. Among pediatric patients, the most common AEs following the use of intravenous peramivir 
are digestive system disorders, such as diarrhea (5-33\%), nausea (2.5\%), and vomiting $(0.5-2 \%)$ [74]. Other adverse reactions that are less common but specific for patients up to the age of 18 years include injection site rash, fever, proteinuria, and tympanic membrane erythema [72,73]. There have also been reports of AEs from post-marketing experience, which are recorded voluntarily, and therefore, it is difficult to determine their frequency and relationship with drug exposure. These adverse effects include anaphylactic reactions, severe dermatological reactions such as Stevens-Johnson syndrome and exfoliative dermatitis, and NPAE-type reactions [72,73]. The potential influence of peramivir on the efficacy of live attenuated influenza vaccines should also be mentioned. It is recommended to avoid vaccinations for 2 days after administration of the drug. Furthermore, peramivir given within 2 weeks of influenza vaccination may adversely affect the immunogenicity of the vaccine [73].

\subsubsection{Laninamivir \\ Drug Presentation}

Due to the serious influenza burden in Asia, great effort is being made in this part of the world to develop effective methods of reducing influenza virus. The result of this work is laninamivir octanoate (LO), a long-acting NAI, discovered and developed by the Japanese pharmaceutical company Daiichi Sankyo. Japan is the first country in the world to approve laninamivir for the treatment of acute uncomplicated influenza A and B. The drug was approved in July 2010 and was launched on the market in October 2010 under the trade name Inavir ${ }^{\circledR}$ (Daiichi Sankyo) $[75,102]$. Since then, Inavir ${ }^{\circledR}$ has been widely used every year to treat seasonal flu infections in Japan, and since 2013, it has been used for prophylaxis against influenza. However, it was never registered and is not available on the European and American markets [102-104].

\section{Pharmacokinetics}

LO is an octanoyl prodrug of laninamivir administered as a powder for oral inhalation. After administration to the lungs, the prodrug is hydrolyzed to its active form, and its concentration remains high for a long time [103]. After a single inhaled dose of $40 \mathrm{mg}$ of LO, the plasma half-life was estimated to be 64.7-74.4 $\mathrm{h}$ in healthy volunteers and $53.2-57.0 \mathrm{~h}$ in patients with renal insufficiency. The drug concentration in the respiratory tract has exceeded the IC50 for influenza virus NA even up to $240 \mathrm{~h}$ after inhalation. The mean plasma Cmax and AUC increase proportionally between doses. The drug concentration in the respiratory tract has been estimated to be 10,000 times higher than the concentration in plasma. The cumulative amounts of urinary LO and laninamivir excreted over $144 \mathrm{~h}$ after LO inhalation account for $>15 \%$ of the human dose. Preclinical animal studies in rats demonstrated that fecal excretion was approximately $36 \%$ following intravenous administration of $\mathrm{LO}$, and the absolute oral bioavailability in rats was minimal (unpublished data). Binding to LO and laninamivir proteins was measured in an in vitro experiment using human plasma and found to be $67 \%$ and $<0.1 \%$, respectively (unpublished data) $[105,106]$. The detailed pharmacokinetics of laninamivir have not yet been fully described. Further research is needed.

\section{Treatment and Prophylaxis with Inhaled Laninamivir}

Inavir $^{\circledR}$ is a prodrug laninamivir octoate available as an oral inhalation powder administered by a disposable dry powder inhaler $[104,107]$. Therapy with laninamivir is based on a single dose of the drug, which is an advantage over zanamivir and oseltamivir therapy. The recommended dose for the treatment of influenza A and B is $20 \mathrm{mg}$ laninamivir in children $<10$ years old and $40 \mathrm{mg}$ in patients $\geq 10$ years old [102-104]. However, studies presented by Murasaka et al. (2017) showed that patients with low peak inspiratory flow are unable to inhale the recommended dose of the drug. Therefore, the drug information sheet suggests that this group of patients requires more inhalations in order to deliver the standard dose to the lungs [107]. For prophylaxis against the influenza virus, the 
recommended dose is $20 \mathrm{mg}$ of laninamivir daily for 2 days for children over 10 years of age, adolescents, and adults [102].

Laninamivir is generally well tolerated in both pediatric and adult patients. No fatalities and no serious AEs have been reported. The main symptoms related to drug administration are cough $(4.72 \%)$, diarrhea $(3.77 \%)$, headache $(3.30 \%)$, and gastritis $(0.47 \%)$, according to clinical trials [76]. The incidence of adverse reactions assessed during post-approval drug safety surveillance was $1.41 \%$ and mainly related to gastrointestinal disorders, such as nausea, vomiting, and diarrhea, and abnormal behavior $(0.45 \%)$, as well as nervous system disorders such as dizziness (0.17\%) [75] (Table 2).

\subsubsection{Comparison of the Effectiveness of NAIs}

The oldest and best known and studied NAIs are zanamivir and oseltamivir. There have been many studies on their effectiveness and safety conducted over 20 years. Over time, the effectiveness of treatment with these two drugs has become a reference point for the evaluation of subsequent NAIs launched on the market, such as peramivir and laninamivir [37,71,72,86,108-110].

Based on two randomized, double-blind, and placebo-controlled trials, Hayden et al. showed the efficiency of zanamivir. Zanamivir for oral inhalation demonstrated the highest clinical response in patients who started treatment up to $30 \mathrm{~h}$ after the onset of symptoms. The mean time to relief of the main symptoms was shortened by 1 day compared to placebo, and in the group of patients with fever who started treatment early (up to $30 \mathrm{~h}$ ), the time to relief of symptoms was reduced by 3 days. It was noted that treatment had better results in patients with fever [41]. On the other hand, the results of the meta-analysis by Heneghan et al., who analyzed 26 studies with zanamivir (Relenza ${ }^{\circledR}$ ), showed that the mean duration of treatment with zanamivir for oral inhalation in adults reduced the time to relief of symptoms by $14.4 \mathrm{~h}$, which is equivalent to 0.6 days [53]. Another study, the double-blind MIST, included children over 12 years of age and adults with influenza symptoms and patients with influenza A and B confirmed by a laboratory test. Study participants were randomized to receive $10 \mathrm{mg}$ of zanamivir for oral inhalation twice daily for 5 days or placebo. The median time to relief of symptoms in patients without fever who were treated with zanamivir was not significantly different from the placebo group, in contrast to febrile patients, who recovered 2 days faster than the placebo group. A significant difference was also observed in the group of high-risk patients, in whom relief of symptoms occurred 2.5 days earlier than in the placebo group on average. Treatment with zanamivir has been shown to be effective for both influenza A and B, and the importance of starting treatment within $36 \mathrm{~h}$ of the onset of symptoms has been emphasized. It was also noted that high-risk patients treated with zanamivir had fewer complications and required fewer antibiotic prescriptions than the placebo group [111]. Another study by Walker et al. drew attention to the beneficial effect of zanamivir for oral inhalation in reducing influenza complications. Early initiation of this drug has been shown to significantly reduce the risk of middleear disorders and middle-ear pressure disorders, which are common complications of influenza [112].

The prophylactic effects of zanamivir have been investigated in several large randomized, double-blind, placebo-controlled trials. All of them were prophylactic, with zanamivir administered at a dose of $10 \mathrm{mg}$ once daily [113-115]. The efficacy of zanamivir in preventing seasonal influenza in healthy adults has been estimated at $67 \%$ for persons with laboratory-confirmed clinical influenza and $84 \%$ for persons with laboratory-confirmed illnesses with fever during seasonal prophylaxis [113]. Post-exposure prophylaxis, as assessed by Hayden et al., was determined to be $79 \%$ effective in protecting against influenza A and B [114]. Similar results were obtained by Monto et al., who estimated a protective efficacy of $82 \%$ against influenza $A$ and B (78\% and $85 \%$, respectively) [115].

Phase 3 clinical trials conducted by Roche on the efficacy and safety of oseltamivir showed that $75 \mathrm{mg}$ of Tamiflu ${ }^{\circledR}$ twice daily for 5 days in the treatment of flu patients with fever shortened the median time to all symptom relief by 1.3 days compared to placebo. 
The study group consisted of adults who received the first dose of the drug within $40 \mathrm{~h}$ of symptom onset. In pediatric patients aged 1-12 years, this time was reduced by 1.5 days, provided that treatment was started in the first $48 \mathrm{~h}$ [67]. Subsequent studies showed that the treatment effect of oseltamivir resulted in a 38\% reduction in disease severity and a 30\% reduction in the median duration of illness onset versus the placebo group. Furthermore, recovery to normal activity was 2-3 days faster in patients treated with oseltamivir versus placebo [116]. A multicenter study from Japan revealed that treatment with oseltamivir started in the first $12 \mathrm{~h}$ after the onset of fever shortened the course of the disease by

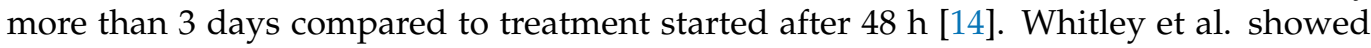
that treatment with oseltamivir started $48 \mathrm{~h}$ after the onset of symptoms in a group of pediatric patients aged 1-12 years with influenza diagnosed based on clinical symptoms reduced disease duration by $36 \mathrm{~h}$ compared to placebo [117]. In this study, treatment with oseltamivir also reduced fever duration, cough, and coryza, with a $44 \%$ reduction in the risk of developing otitis media [117].

In another study by Hayden et al., treatment with oseltamivir shortened, though not significantly, the time to alleviation of symptoms by $16.8 \mathrm{~h}$ in the adult group and by $29 \mathrm{~h}$ in children with uncomplicated flu, but it had no effect in children with asthma [53].

Many factors, including mortality, risk of hospitalization, duration of hospitalization, and risk of complications in the form of pneumonia, have been considered and analyzed in the context of treatment with oseltamivir, but a clear answer remains to be found $[12,14,37,53,58]$. On the other hand, the effectiveness of seasonal and post-exposure prophylaxis in neonates, children, adults, and the elderly using oseltamivir is indisputable and confirmed by many studies to range from 70 to $90 \%$ [12,14,53,58,118-120].

Two randomized controlled trials of the combination of zanamivir and oseltamivir were conducted to improve the effectiveness of NAI treatment. Both provided similar results, with no additional benefits of these treatments. Interestingly, oseltamivir monotherapy turned out to be more effective than the combination therapy [121,122].

Zanamivir administered intravenously to hospitalized adult patients with severe influenza, including those requiring intensive care, reduced the number of patients in the ICU by $40 \%$ in the largest randomized double-dummy phase 3 trial [84]. Patients were divided into three groups depending on the type of therapy used: group 1, $600 \mathrm{mg}$ of intravenous zanamivir twice daily; group 2, $300 \mathrm{mg}$ of intravenous zanamivir twice daily; and group 3, $75 \mathrm{mg}$ of oral oseltamivir twice daily for 5 days, with the option of extending the treatment for another 5 days if necessary. The median time to improvement was 5.14 days in group 1, 5.87 days in group 2, and 5.63 days in group 3. These differences were not significant, and treatment with intravenous zanamivir at both doses was considered as effective as treatment with oseltamivir. The overall mortality was $7 \%$; it was similar in all groups and consistent with previous reports on NAI treatment in hospitalized patients [84]. A phase 2 open-label, multicenter, single-arm study of the efficacy of intravenous zanamivir in hospitalized children reported a $92 \%$ positive clinical response to the assumed endpoints and a $7 \%$ mortality rate [86].

Peramivir was first evaluated for safety and efficacy in the double-blind, placebocontrolled, phase 2 trial conducted by Kohno et al. Adult patients with uncomplicated seasonal influenza virus infection were divided into three groups to receive a single intravenous dose of peramivir (600 $\mathrm{mg}$ or $300 \mathrm{mg}$ ) or a placebo [123]. The study showed that the time to relief of symptoms was significantly shortened in patients treated with peramivir, regardless of the influenza subtype [123]. Subsequent large phase 2 and 3 studies comparing the efficacy of a single dose of intravenous peramivir versus oral oseltamivir (75 mg 2xd) showed a comparable effect on time to clinical stability and symptom duration in both seasonal uncomplicated influenza patients and hospitalized patients [124,125]. Moreover, Koho et al. showed that treatment with a single dose of peramivir shortens the duration of fever by $3 \mathrm{~h}$ compared to oseltamivir treatment ( $<34 \mathrm{~h}$ vs. $<37 \mathrm{~h}$, respectively) and may be an equivalent alternative to treatment with 5 days of oseltamivir [124]. Two retrospective studies demonstrated the superiority of peramivir over other NAIs in terms 
of fever duration in pediatric patients [126,127]. Both studies concerned the treatment analysis of all four NAIs (zanamivir, oseltamivir, peramivir, and laninamivir). The first study showed that, in children infected with influenza A/H3N2, the median duration of fever after treatment with peramivir was significantly (3.3 times) shorter than after treatment with oseltamivir [126]. The second study in children 5-18 years of age showed that, in children with influenza A treated with peramivir, the median duration of fever was 1 day shorter than after treatment with zanamivir and 2 days shorter in children with influenza B treated with peramivir compared to treatment with laninamivir [127].

A multinational phase 3 study compared the efficacy of laninamivir administered as a single inhaled dose at $20 \mathrm{mg}$ or $40 \mathrm{mg}$ versus oseltamivir phosphate at $75 \mathrm{mg} 2$ times per day for 5 days [128]. This study found that the effects of treatment with laninamivir and oseltamivir are comparable in regard to reducing the duration of symptoms and shedding the virus. Laninamivir at $40 \mathrm{mg}$ demonstrated a better effect than $20 \mathrm{mg}$ and was effective in the treatment of infections (especially of children) caused by oseltamivirresistant influenza A/H1N1 (H274Y) [128]. In another large observational study, Mawatori et al. compared the efficacy of treatment with four NAIs in patients with influenza A/H1N1, A/H3N2, and B. The results showed that the laninamivir-treated group had a significantly longer duration of fever compared to patients treated with oseltamivir for both types of infections (influenza A and B) [129]. The results of this study are consistent with previous research $[109,127,130]$. In contrast, the use of laninamivir for the post-exposure prevention of influenza has significant benefits. A double-blind, randomized, placebo-controlled study conducted by Kashiwagi et al. showed a $62.8 \%$ reduction in the incidence rate compared to placebo [131].

\subsection{Cap-Dependent Endonuclease Inhibitors-New Group of Anti-Influenza Drugs}

\subsubsection{Baloxavir Marboxil}

After nearly 20 years, a new class of anti-influenza drug was approved in 2018, first in Japan and then in the United States. Baloxavir marboxil is a cap-dependent endonuclease inhibitor (CENI), an antiviral drug against influenza A and B viruses, including oseltamivirresistant strains $[17,132]$. This drug was registered in the European Union market in July 2021 under the trade name Xofluza ${ }^{\circledR}$ (Roche), with the indication for treatment of acute uncomplicated influenza and post-exposure prophylaxis [133]. Recently, in the United States, the indications for the use of Xofluza ${ }^{\circledR}$ have been extended to treating patients with a high risk of developing influenza-related complications [132].

\subsubsection{Mode of Action}

Baloxavir marboxil is a small-molecule prodrug that, after oral administration, is hydrolyzed in the intestinal epithelial cells, blood, and liver to the active form baloxavir acid [7]. Active baloxavir inhibits influenza virus replication by selective binding of the RNA-dependent influenza virus RNA polymerase complex to the PA protein [15,17]. The transcription of vRNA is carried out in the nuclei of host cells by a specific polymerase. This enzyme is composed of three subunits: PB1, PB2, and PA [19]. Baloxaviric acid inhibits viral mRNA formation by specific binding of the PA protein, which is responsible for capturing the host cell mRNA cap and a key step in initiating the process of vRNA transcription $[15,17,134]$.

The prodrug baloxavir marboxil has a phenolic hydroxyl group to enhance oral absorption. The drug was designed based on the Dolutegravir DTG molecule, a drug used in the treatment of HIV infections. When creating the baloxavir molecule, a DTG molecule chelating metals in the active site of viral integrase was used as a chemical scaffold. Limited information is available on the mechanism of baloxavir binding to PA and on potential determinants of reduced susceptibility [135].

Structurally, the baloxavir molecule resembles butterfly wings, where one of the wings contains a chelating frontal metal, the oxazine-pyridotriazinedione polar group, and the other wing contains a lipophilic difluoro-dihydrodibenzothiepin tail group that connects 
to the active site through van der Waals interactions. At the endonuclease active site, the head group binds to two divalent cations, and each metal ion has octahedral coordination through interactions with a protein. The first active site binds preferentially to manganese, and acid residues His41, Glu119, and Asp108 are present, whereas the second active site partially binds manganese and magnesium and has the acid residues Asp108 and Glu80. In influenza A, baloxavir forms van der Waals interactions with Ala20 and Tyr24 from the C-terminal end of the $\alpha-2$ helix and Lys34, Ala37, and Ile38 from the $\alpha-3$ helix, as shown in Figure 3.

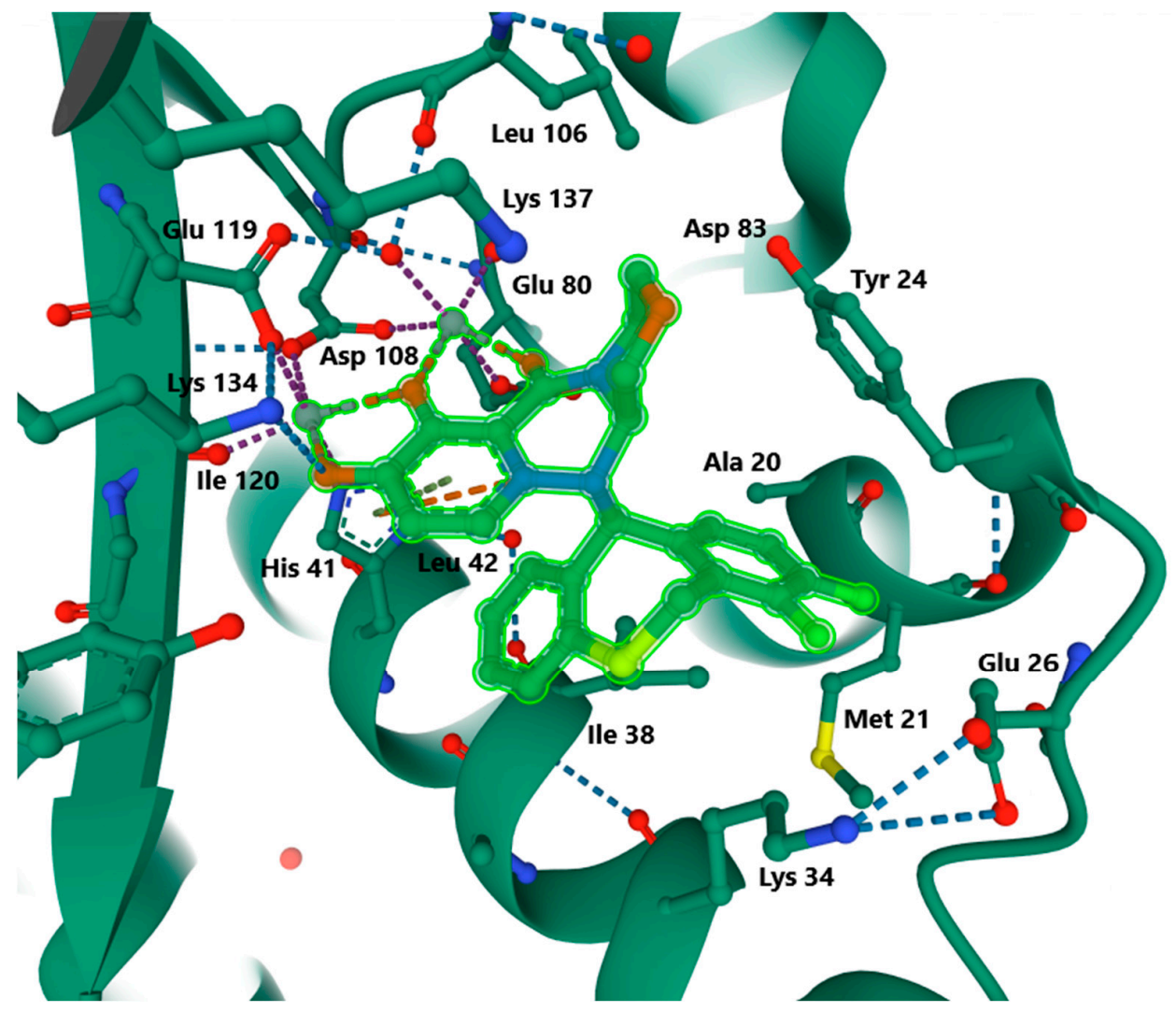

Figure 3. Influenza virus endonuclease complexed with baloxavir acid.

In influenza B, however, similar interactions occur with other residues: Thr20, Phe24, Met34, Asn37, and Ile38. Both types of van der Waals interactions take place through CG1 and CD1 atoms. In addition, a hydrogen bond is formed with the carbonyl oxides of the main Met34 and Leu35 chain. Due to these bonds and interactions with the PA protein molecule, the endonuclease is inhibited [136].

\subsubsection{Pharmacokinetics of Baloxavir}

Baloxavir marboxil is administered orally as a prodrug that is hydrolyzed to baloxaviric acid in the gastrointestinal tract. Arylacetamine deacetylase (AADAC) is responsible for metabolizing the drug in the lumen of the gastrointestinal tract, intestinal epithelium, and liver. Maximum plasma concentrations of baloxaviric acid are reached 3.5-4 $\mathrm{h}$ after administration. Over the dose range of 6-80 mg, baloxaviric acid exhibits linear pharmacokinetics and is eliminated in the liver by glucuronidation and, to a lesser extent, cytochrome P450 3A4 oxidation. The mean terminal elimination half-life is $80 \mathrm{~h}$. More than $80 \%$ of the drug is excreted in the feces $[137,138]$.

\subsubsection{Treatment and Prophylaxis with Oral Baloxavir}

The active component of Xofluza ${ }^{\circledR}$ (Roche) is baloxavir marboxil. Its pharmaceutical form is white to pale yellow, film-coated, oval-shaped tablets for oral use. In the countries 
of the European Union, the indication for the use of the drug is the treatment of acute uncomplicated influenza and post-exposure prophylaxis, whereas in the United States, Xofluza ${ }^{\circledR}$ has not been approved for prevention and is indicated for the treatment of acute uncomplicated influenza in healthy patients and patients at high risk of developing influenza-related complications. The drug is intended for use in adolescents and adults 12 years of age and older. According to medical guideline recommendations, oral baloxavir should be administered within $48 \mathrm{~h}$ of illness onset or up to $48 \mathrm{~h}$ after close contact with a person infected with the influenza virus [132,139]. Due to the long half-life of baloxavir, $>79 \mathrm{~h}$, a single-dose regimen is recommended. The dosage is based on body weight: one dose of $40 \mathrm{mg}$ for a patient weighing $40-79 \mathrm{~kg}$ and one dose of $80 \mathrm{mg}$ for a patient weighing $\geq 80 \mathrm{~kg}$ (Table 3) $[61,64-66,73,102,104,109,139]$. The drug can be taken with food, except those which contain high levels of calcium. It is also not recommended to combine baloxavir treatment with the administration of a live attenuated influenza vaccine [132,139].

Table 3. Indication and dosage of anti-influenza medications.

\begin{tabular}{|c|c|c|c|c|}
\hline Drug & $\begin{array}{l}\text { Therapeutic } \\
\text { Indication }\end{array}$ & Age Interval & $\begin{array}{l}\text { Pharmaceutical } \\
\text { Form }\end{array}$ & Dose \\
\hline \multirow[t]{2}{*}{ Zanamivir } & $\begin{array}{l}\text { Treatment of } \\
\text { acute } \\
\text { uncomplicated } \\
\text { influenza A } \\
\text { and B }\end{array}$ & $\begin{array}{l}\geq 5 \text { years and } \\
\text { older ( } \geq 7 \text { years } \\
\text { in USA and } \\
\text { Canada) }\end{array}$ & \multirow[t]{2}{*}{$\begin{array}{l}\text { Powder for oral } \\
\text { inhalation }\end{array}$} & $\begin{array}{l}10 \text { mg twice daily } \\
\text { for } 5 \text { days }\end{array}$ \\
\hline & $\begin{array}{l}\text { Post-exposure } \\
\text { prophylaxis } \\
\text { Seasonal } \\
\text { prophylaxis }\end{array}$ & $\begin{array}{l}\geq 5 \text { years and } \\
\text { older } \\
(\geq 7 \text { years in } \\
\text { Canada })\end{array}$ & & $\begin{array}{l}10 \mathrm{mg} \text { once daily for } \\
10 \text { days } \\
10 \mathrm{mg} \text { once daily for } \\
28 \text { days }\end{array}$ \\
\hline Zanamivir & $\begin{array}{l}\text { Treatment of } \\
\text { hospitalized } \\
\text { seriously ill } \\
\text { patients }\end{array}$ & $\begin{array}{l}\geq 6 \text { months and } \\
\text { older }\end{array}$ & $\begin{array}{l}\text { Solution for } \\
\text { infusion }\end{array}$ & $\begin{array}{l}\text { Weight-based dose } \\
6 \text { months }<6 \text { years } \\
14 \text { mg per kg } 2 x d \geq \\
6<18 \text { years } 12 \mathrm{mg} \\
\text { per } \mathrm{kg} 2 \text { xd Adults }> \\
50 \mathrm{~kg} 600 \text { md } 2 x d \\
\text { for } 5-10 \text { days }\end{array}$ \\
\hline \multirow[t]{3}{*}{ Oseltamivir } & $\begin{array}{l}\text { Treatment of } \\
\text { acute } \\
\text { uncomplicated } \\
\text { influenza A } \\
\text { and B }\end{array}$ & $\begin{array}{l}\text { No age limits } \\
\quad \text { (EU) } \\
\geq 2 \text { weeks and } \\
\text { older (USA) }\end{array}$ & \multirow[t]{3}{*}{$\begin{array}{l}\text { Capsules } 30 \mathrm{mg} \text {, } \\
45 \mathrm{mg}, 75 \mathrm{mg} \\
\text { Oral suspension }\end{array}$} & $\begin{array}{c}\geq 13 \text { years: } 75 \mathrm{mg} \\
2 x d \text { for } 5 \text { days } \\
<13 \text { years } \\
\text { old-weight-based } \\
\text { dose }\end{array}$ \\
\hline & $\begin{array}{l}\text { Post-exposure } \\
\text { prophylaxis }\end{array}$ & $\geq 1$ year old & & $\begin{array}{c}\geq 13 \text { years: } 75 \mathrm{mg} \\
1 \times d \text { for } 10 \text { days } \\
\text { at least }\end{array}$ \\
\hline & $\begin{array}{l}\text { Seasonal } \\
\text { prophylaxis }\end{array}$ & $\begin{array}{l}\text { No age limits } \\
\text { (EU) }\end{array}$ & & $\begin{array}{c}75 \mathrm{mg} 1 \mathrm{xd} \text { for up to } \\
6 \text { weeks }\end{array}$ \\
\hline \multirow[t]{2}{*}{ Peramivir } & $\begin{array}{l}\text { Treatment of } \\
\text { acute } \\
\text { uncomplicated } \\
\text { influenza A } \\
\text { and B }\end{array}$ & $\geq 18$ years old & \multirow[t]{2}{*}{$\begin{array}{l}\text { Solution for } \\
\text { infusion }\end{array}$} & $\begin{array}{c}2 \text { years } \leq 12 \text { years } \\
\text { single } 12 \mathrm{mg} / \mathrm{kg}\end{array}$ \\
\hline & & & & $\begin{array}{l}\text { Adults: single } \\
600 \text { mg i.v. }\end{array}$ \\
\hline
\end{tabular}


Table 3. Cont.

\begin{tabular}{|c|c|c|c|c|}
\hline Drug & $\begin{array}{l}\text { Therapeutic } \\
\text { Indication }\end{array}$ & Age Interval & $\begin{array}{c}\text { Pharmaceutical } \\
\text { Form }\end{array}$ & Dose \\
\hline Laninamivir & $\begin{array}{c}\text { Treatment } \\
\text { of acute } \\
\text { uncomplicated } \\
\text { influenza A } \\
\text { and B } \\
\text { Post-exposure } \\
\text { prophylaxis }\end{array}$ & No age limits & $\begin{array}{l}\text { Oral inhalation } \\
\text { powder }\end{array}$ & $\begin{array}{c}<10 \text { years } 20 \mathrm{mg} \\
\text { single dose } \\
\geq 10 \text { years } 40 \mathrm{mg} \\
\text { single } \\
<10 \text { years } 20 \mathrm{mg} \\
\text { single dose } \\
\geq 10 \text { years } 40 \mathrm{mg} \\
\text { single dose }\end{array}$ \\
\hline $\begin{array}{l}\text { Baloxavir } \\
\text { marboxil }\end{array}$ & $\begin{array}{l}\text { Treatment of } \\
\text { acute } \\
\text { uncomplicated } \\
\text { influenza A } \\
\text { and B } \\
\text { (healthy and } \\
\text { high risk of } \\
\text { complications } \\
\text { in USA) } \\
\text { Post-exposure } \\
\text { prophylaxis } \\
\text { (in EU) }\end{array}$ & $\geq 12$ years old & $\begin{array}{l}\text { Tablets for } \\
\text { oral use }\end{array}$ & $\begin{array}{l}\text { Weight-based dose } \\
40>80 \mathrm{~kg} \\
40 \mathrm{mg} \text { single dose } \\
\geq 80 \mathrm{~kg} \\
80 \mathrm{mg} \text { single dose }\end{array}$ \\
\hline
\end{tabular}

\subsubsection{Safety of Baloxavir}

Safety data for baloxavir marboxil come from two randomized, double-blind, phase 3 clinical studies, CAPSTONE-1 and CAPSTONE-2, with the latter enriched with a group of patients at high risk of influenza complications. Analysis of data from these studies revealed a significantly lower incidence of AEs reported in the baloxavir group compared to the oseltamivir group. The most commonly reported AEs included diarrhea, nausea, bronchitis, sinusitis, and headache. They occurred in at least 1 out of 100 participants [7]. Other reports from post-marketing experience with baloxavir have shown the possibility of serious adverse reactions, such as anaphylactic shock; anaphylactic reactions; swelling of the face, eyelids, and tongue; erythema multiforme; rash; colitis; bloody diarrhea; and psychiatric events, such as abnormal behavior, delirium, and hallucination. The frequency and correlation between AEs and baloxavir cannot be determined due to the voluntary nature of these reports from unknown population sizes [7,132].

Further research is currently being carried out on the safety and effectiveness of baloxavir. The results from one such study, the phase 3 clinical trial MiniSTONE 2, enrolling pediatric participants with influenza-like symptoms aged 1-12 years, are similar to those reported in adults. The most common AEs were gastrointestinal disorders (diarrhea and vomiting), and the frequency of all reported effects was $46.1 \%$ for treatment with baloxavir and $53.4 \%$ for treatment with oseltamivir [140]. However, the drug is not registered for the treatment of patients in this age group and requires further research before a possible extension of the registration [132,133].

\subsubsection{Effectiveness of Baloxavir}

The first study of baloxavir antiviral efficacy was a phase 2 study examining the dose-response and antiviral activity of the drug. The results of this study were promising, as they showed a reduction in time to symptom relief in all baloxavir groups compared to placebo and a significantly greater reduction in virus titer within $24 \mathrm{~h}$ after baloxavir treatment compared to placebo; the data allowed the identification of the best baloxavir dose (40 $\mathrm{mg}$ and $80 \mathrm{mg}$ weight-dependent) for further phase 3 studies [141].

Another study was CAPSTONE-1, a multicenter, double-blind, randomized study conducted to evaluate the efficacy of a single dose of baloxavir marboxil. The study 
participants were 1436 healthy patients with influenza aged 12-64 years, separated into adolescents (12-19 years) and adults (20-64 years). Adolescents were randomized into two groups, baloxavir and placebo, whereas adults were separated into three groups: baloxavir, oseltamivir, and placebo. Depending on the group, the following treatment was applied: single-dose baloxavir at $40 \mathrm{mg}$ or $80 \mathrm{mg}$, 5-day oseltamivir at $75 \mathrm{mg}$ twice daily, or placebo. Treatment was started within the first $48 \mathrm{~h}$ after the onset of flu symptoms. The results revealed the superiority of baloxavir over placebo on par with oseltamivir. Compared to placebo, both baloxavir and oseltamivir showed a significant reduction in time to the alleviation of symptoms (placebo $80.2 \mathrm{~h}$, baloxavir $53.7 \mathrm{~h}$, and oseltamivir $53.8 \mathrm{~h}$; Table 4). Baloxavir also resulted in a significant reduction in the median time to fever resolution; the effect was achieved $17.5 \mathrm{~h}$ earlier than in the case of placebo ( $24.5 \mathrm{~h}$ vs. $42 \mathrm{~h}$, respectively). Another important point to evaluate the effectiveness of baloxavir therapy was the median time to return to normal health, which was $129.2 \mathrm{~h}$ in the case of baloxavir and $168.8 \mathrm{~h}$ in the case of placebo, but this difference was not significant. On the other hand, clear differences were noted in terms of the median duration of virus detection, which was $24 \mathrm{~h}$ in the baloxavir group versus $72 \mathrm{~h}$ in the oseltamivir group and $96 \mathrm{~h}$ in the placebo group $[17,134,142]$.

Table 4. The effectiveness of anti-influenza drugs.

\begin{tabular}{|c|c|c|c|}
\hline Type of Treatment & Primary End Point & Effect & Study \\
\hline $\begin{array}{l}\text { Zanamivir vs. placebo } \\
\text { given up to } 30 \mathrm{~h} \text { of } \\
\text { symptom onset }\end{array}$ & TTAS * & $\begin{array}{l}1 \text { day shorter with } \\
\text { zanamivir }\end{array}$ & $\begin{array}{l}\text { Hayden et al. } \\
\text { [41] }\end{array}$ \\
\hline $\begin{array}{l}\text { Zanamivir vs. placebo } \\
\text { (patients with fever) } \\
\text { given up to } 30 \mathrm{~h} \text { of } \\
\text { symptom onset }\end{array}$ & TTAS & $\begin{array}{l}3 \text { days shorter with } \\
\text { zanamivir }\end{array}$ & $\begin{array}{l}\text { Hayden et al. } \\
\text { [41] }\end{array}$ \\
\hline Zanamivir vs. placebo & TTAS & $\begin{array}{l}0.6 \text { day }(14.4 \mathrm{~h}) \text { shorter } \\
\text { with zanamivir }\end{array}$ & Heneghan et al. [53] \\
\hline $\begin{array}{l}\text { Zanamivir vs. placebo } \\
\text { (patients without fever) }\end{array}$ & TTAS & $\begin{array}{c}0 \\
\text { (no significant differences) }\end{array}$ & $\begin{array}{l}\text { The MIST Study Group } \\
\text { [111] }\end{array}$ \\
\hline $\begin{array}{l}\text { Zanamivir vs. placebo } \\
\text { (patients with fever) }\end{array}$ & TTAS & $\begin{array}{l}2 \text { days shorter } \\
\text { with zanamivir }\end{array}$ & $\begin{array}{l}\text { The MIST Study Group } \\
\text { [111] }\end{array}$ \\
\hline $\begin{array}{l}\text { Zanamivir vs. placebo } \\
\text { (high-risk patients) }\end{array}$ & TTAS & $\begin{array}{l}2.5 \text { days shorter } \\
\text { with zanamivir }\end{array}$ & $\begin{array}{l}\text { The MIST Study Group } \\
\text { [111] }\end{array}$ \\
\hline $\begin{array}{c}\text { Dectova vs. oseltamivir } \\
\text { (patients hospitalized in serious } \\
\text { condition and ICU }{ }^{* *} \text { patients) }\end{array}$ & TTAS & Similar effect & $\begin{array}{c}\text { Marty et al. } \\
\text { [84] }\end{array}$ \\
\hline $\begin{array}{l}\text { Oseltamivir vs. placebo } \\
\text { (adult patients with fever) }\end{array}$ & TTAS & $\begin{array}{l}1.3 \text { days shorter } \\
\text { with oseltamivir }\end{array}$ & $\begin{array}{c}\text { Tamiflu summary of product } \\
\text { characteristics } \\
{[67]}\end{array}$ \\
\hline $\begin{array}{l}\text { Oseltamivir vs. placebo } \\
\text { (pediatric patients) }\end{array}$ & TTAS & $\begin{array}{l}1.5 \text { days shorter } \\
\text { with oseltamivir }\end{array}$ & $\begin{array}{c}\text { Tamiflu summary of product } \\
\text { characteristics } \\
{[67]}\end{array}$ \\
\hline $\begin{array}{c}\text { Peramivir } 200 \mathrm{mg} \text { or } 400 \mathrm{mg} \\
\text { vs. oseltamivir } \\
\text { (hospitalized patients) }\end{array}$ & Time to clinical stability & $\begin{array}{c}\text { P200mg-31.0 h } \\
\text { P400mg-24.3 h } \\
\text { Oseltamivir-35.5 h }\end{array}$ & $\begin{array}{l}\text { Ison et al. } \\
\text { [125] }\end{array}$ \\
\hline $\begin{array}{c}\text { Peramivir } 300 \mathrm{mg} \text { or } 600 \mathrm{mg} \\
\text { vs. oseltamivir }\end{array}$ & TTAS & $\begin{array}{l}\text { P300mg-78.0 h } \\
\text { P600mg-81.0 h } \\
\text { Placebo-81.8 h }\end{array}$ & $\begin{array}{l}\text { Kohno et al. } \\
\quad[124]\end{array}$ \\
\hline
\end{tabular}


Table 4. Cont.

\begin{tabular}{|c|c|c|c|}
\hline Type of Treatment & Primary End Point & Effect & Study \\
\hline $\begin{array}{l}\text { Peramivir vs. oseltamivir } \\
\text { (pediatric patients) }\end{array}$ & Fever duration & $\begin{array}{c}\text { A significant advantage of } \\
\text { peramivir }\end{array}$ & $\begin{array}{c}\text { Shobugawa et al. } \\
\text { [126] }\end{array}$ \\
\hline $\begin{array}{l}\text { Peramivir vs. zanamivir } \\
\text { inhalation } \\
\text { (pediatric patients) }\end{array}$ & Fever duration & $\begin{array}{l}\text { Peramivir } 1 \text { day shorter } \\
\text { than zanamivir }\end{array}$ & $\begin{array}{l}\text { Hikita et al. } \\
\text { [127] }\end{array}$ \\
\hline Peramivir vs. laninamivir & Fever duration & $\begin{array}{l}\text { Peramivir } 1 \text { day shorter } \\
\text { than laninamivir }\end{array}$ & $\begin{array}{l}\text { Hikita et al. } \\
\text { [127] }\end{array}$ \\
\hline $\begin{array}{c}\text { Laninamivir } 20 \mathrm{mg} \text { or } 40 \mathrm{mg} \\
\text { vs. oseltamivir }\end{array}$ & TTAS & $\begin{array}{l}\text { L20mg-85.8 h } \\
\text { L40-73.0 h } \\
\text { Os-73.6 h }\end{array}$ & Watanabe et al. [128] \\
\hline $\begin{array}{l}\text { Baloxavir vs. placebo } \\
\text { (adolescents) }\end{array}$ & TTAS & $\begin{array}{l}\text { Baloxavir-53.7 h } \\
\text { Placebo-80.2 h }\end{array}$ & $\begin{array}{c}\text { CAPSTONE-1 } \\
\text { [142] }\end{array}$ \\
\hline $\begin{array}{l}\text { Baloxavir vs. oseltamivir } \\
\text { vs. placebo } \\
\text { (adult patients) }\end{array}$ & TTAS & $\begin{array}{l}\text { Baloxavir-53.7 h } \\
\text { Oseltamivir }-53.8 \mathrm{~h} \\
\text { Placebo-80.0 h }\end{array}$ & $\begin{array}{l}\text { CAPSTONE-1 } \\
\text { [142] }\end{array}$ \\
\hline Baloxavir vs. placebo & Fever duration & $\begin{array}{l}\text { Baloxavir-24.5 h } \\
\text { Placebo-42 h }\end{array}$ & $\begin{array}{c}\text { CAPSTONE-1 } \\
\text { [142] }\end{array}$ \\
\hline $\begin{array}{l}\text { Baloxavir vs. oseltamivir } \\
\text { vs. placebo }\end{array}$ & TTAS & $\begin{array}{l}\text { Baloxavir-73.2 h } \\
\text { Oseltamivir-81.0 h } \\
\text { Placebo-102.3 h }\end{array}$ & $\begin{array}{c}\text { CAPSTONE-2 } \\
{[143]}\end{array}$ \\
\hline $\begin{array}{l}\text { Baloxavir vs. oseltamivir } \\
\text { (pediatric patients) }\end{array}$ & TTAS & $\begin{array}{l}\text { Baloxavir-138.1 h } \\
\text { Oseltamivir-150.0 h }\end{array}$ & $\begin{array}{c}\text { MiniSTONE } \\
\text { [144] }\end{array}$ \\
\hline
\end{tabular}

* TTAS-time to alleviation of symptoms; ** ICU—intensive care unit.

Another phase 3 study was CAPSTONE-2, a multicenter, double-blind, randomized study of baloxavir marboxil in participants with influenza at high risk of influenza complications. The study was performed analogously to CAPSTONE-1 in three groups with baloxavir, oseltamivir, or placebo treatment. A total of 2184 patients participated in the study. The CAPSTONE-2 results showed that the median time to improvement of influenza symptoms in the baloxavir group was significantly shorter than in the placebo group and similar to the oseltamivir group (73.2 h, $102.3 \mathrm{~h}$, and $81.0 \mathrm{~h}$, respectively). However, for influenza B infection, the median time to improvement of influenza symptoms in the baloxavir group was $27.1 \mathrm{~h}$ shorter than with oseltamivir. In addition, this time was significantly shorter in patients who started treatment in the first $12 \mathrm{~h}$ after symptom onset, and in the baloxavir group, it differed by $48 \mathrm{~h}$ on average compared to placebo. Treatment with baloxavir proved to be as effective as oseltamivir in terms of the time to fever resolution, averaging $30.8 \mathrm{~h}$ for baloxavir and $34.3 \mathrm{~h}$ for oseltamivir. Both drugs showed significant efficacy compared to placebo, with a median time to fever resolution of $50.7 \mathrm{~h}$. However, in terms of the speed of recovery, no significant changes were found between the three groups (baloxavir $126.4 \mathrm{~h}$, oseltamivir $126.9 \mathrm{~h}$, and placebo $149.8 \mathrm{~h}$ ). The influenza virus transmission data were similar to the CAPSTONE-1 results and showed that the decrease in virus titer in baloxavir-treated patients occurred much faster than in those treated with oseltamivir or placebo $[143,145]$.

MiniSTONE2, a phase 3 multicenter, double-blind, randomized active (oseltamivir) controlled study, was conducted in children aged 1-12 years. The efficacy of influenza treatment with baloxavir was a secondary endpoint of this study. The results showed that the effectiveness of treating influenza in children was comparable between baloxavir and oseltamivir. The mean time to symptom relief was $138.1 \mathrm{~h}$ in the baloxavir group and $150.0 \mathrm{~h}$ in the oseltamivir group $[140,144]$. Phase 3 clinical trials are currently underway on the safety and efficacy of baloxavir marboxil in healthy pediatric participants (from 
newborn to 1 year old) with influenza-like symptoms. Completion of the research and publication of the results is planned for August 2022 [146].

The preventive efficacy of baloxavir in individuals exposed to influenza patients has also been investigated. Ikematsu et al. presented the results of a multicenter, double-blind, randomized, placebo-controlled clinical trial conducted in Japan during the 2018-2019 influenza season. In this study, $1.9 \%$ of participants using single-dose baloxavir presented with clinical symptoms of influenza confirmed by a laboratory test, compared to $13.6 \%$ of participants using placebo. Thus, baloxavir showed significant efficacy in preventing influenza after contact with a sick household member [147]. A retrospective study conducted by Umemura et al. analyzed the transmission of the influenza virus in home contacts and revealed that treatment of a flu patient with baloxavir vs. oseltamivir equally limited the source of infection for healthy household members [148].

\section{Current Studies}

The rapid evolution of the influenza virus, leading to a reduction in vaccine effectiveness and the emergence of drug-resistant strains, is driving continuous research into the development of new antiviral drugs. Currently, research is focused on several directions, including substances of synthetic, biological (bacterial), and plant origins.

One potential antiviral drug candidate is 1,3-dihydroxy-6-benzo [c] chromene (D715-2441). This is a small-molecule inhibitor that exhibits significant inhibitory activity against influenza A virus in vitro. Liu et al. showed that D715-2441 has antiviral activity against many types of influenza A virus, including H1N1, H3N2, H5N1, and H7N9, as well as oseltamivir-resistant strains with the H274Y NA mutation. The main target of the molecule is the early stage of viral replication. D715-2441 binds specifically to the PB2 protein, markedly inhibiting the activity of influenza RNA polymerase. In addition, simultaneous application of the tested molecule with zanamivir results in a synergistic antiviral effect [149].

Another promising compound is the novel compound FA-6005. In vitro studies have shown that this small molecule exhibits broad antiviral activity against human influenza A and B viruses. FA-6005 suppresses influenza virus replication and disrupts the intracellular transport of vRNP at many stages. This molecule interferes with various stages in the life cycle of influenza virus, including the processes of adsorption, entry, replication, transcription, and export. The molecular target of FA-6005 is amino acid residue 41, thereby inhibiting the activity of the vRNP complex. The interaction of FA-6005 has been shown to reduce NP/vRNP export, impair the trafficking of circulating RNPs in the cytoplasm, perturb the virus uncoating process and vRNP import, and lead to disruption of the budding of daughter virions [150].

Tests on bacterial RNA have also shown the inhibitory effect of FA-6005 on the influenza virus. In an in vivo study, heat-killed Lactobacillus plantarum SNK12 (SNK) and Enterococcus faecalis $\mathrm{KH} 2$ (KH2) strains were orally administered to mice infected with influenza A virus. In this study, Watanabe et al. showed that orally administered SNK and KH2 inhibited viral replication and increased the immune response [151].

Phytochemicals are also undergoing extensive research in the context of controlling influenza virus. One of them investigated the effect of catechin and gallic acid from Toona sinensis Roem leaves on influenza virus A (H1N1) in cell cultures. The study showed inhibition of viral replication and its adhesion to host cells by regulating cytokines and adhesion molecules (fractalkine, E-selectin, IL-8, VCAM-1, and ICAM-1) [152]. A follow-up to this study determined a 50\% effective inhibitory concentration (EC50) of gallic acid and catechin for influenza A (H1N1) of $2.6 \mu \mathrm{g} / \mathrm{mL}$ and $18.4 \mu \mathrm{g} / \mathrm{mL}$, respectively, and $50 \%$ cytotoxic concentration (CC50) of $22.1 \mu \mathrm{g} / \mathrm{mL}$ and $>100 \mu \mathrm{g} / \mathrm{mL}$ for gallic acid and catechins, respectively. These results indicate that gallic acid is a sensitive substance for inhibiting influenza A (H1N1) infection and that catechin is a safe substance for long-term use in preventing influenza virus infection [153]. 
All of the above studies represent a promising step towards the development of new anti-influenza drugs. However, they need to be further investigated at the preclinical and clinical levels.

\section{Discussion}

Out of the three groups of anti-influenza drugs, only two are currently used in therapy and prophylaxis, NAI and CENI [8,49]. NAIs, including zanamivir, oseltamivir, peramivir, and laninamivir, are the most common group of drugs for influenza [37-39]. CENIs, on the other hand, are a completely new class of drugs with a unique representative recently available on the market, baloxavir marboxil $[17,140]$. The main difference between NAIs and CENIs is the mechanism of action [57].

Each of the drugs listed above has a unique feature that distinguishes it from the rest. Baloxavir stands out among the oral medications available in Europe for its singledose therapy. This is its advantage over oseltamivir, which is by far the most widely used anti-influenza drug. Oseltamivir therapy requires a considerable regimen, as it lasts 5 days, and the capsules should be taken twice a day at $12 \mathrm{~h}$ intervals, which may cause a problem for some groups of patients, such as children [87,139]. Aside from baloxavir, laninamivir and peramivir are also single-dose medications. Such a dosing regimen is an ideal therapeutic solution in the face of the fight against drug resistance, which is favored by a break in treatment.

In the group of drugs for oral use, oseltamivir has the advantage of potential administration in the form of oral suspension, which is convenient for patients who have problems swallowing tablets or for whom the use of inhaled drugs poses an increased risk, such as patients with asthma [69]. In severe cases of influenza, in patients requiring hospitalization and sometimes extracorporeal membrane oxygenation (ECMO), intravenous infusion is often the best route of drug administration. This group of drugs includes zanamivir (Dectova $^{\circledR}$ ) and peramivir (Rapivap ${ }^{\circledR}$ ), but only the former is approved for the treatment of seriously ill patients and life-threatening conditions [65,73].

All currently recommended antiviral drugs against influenza have a favorable safety profile. The most common AEs occurring with oseltamivir, intravenous zanamivir, peramivir, laninamivir, and baloxavir are headache and gastrointestinal disturbances, such as vomiting, nausea, and diarrhea $[7,65,67,71,73,75,123]$. These AEs usually accompany the first dose of the drug and disappear within the first 2 days of therapy. To alleviate these symptoms, it is recommended to take the drugs in the form of tablets or capsules with food [54,132]. The exception is zanamivir for inhalation (Relenza ${ }^{\circledR}$ ), which is most often associated with disorders of the respiratory system [64]. NPAEs have been reported for all recommended anti-influenza medications. However, due to the fact that they come mainly from postmarketing surveillance and the specificity of flu symptoms, which are often associated with fever, it has not been possible to closely link these incidents to the use of any antiviral agent. Due to the serious nature of these symptoms, they require further attention and research $[7,26,64,66,72]$.

The effectiveness of anti-influenza drugs has been the subject of many studies (Table 4). The key factor in increasing the effectiveness of therapy, regardless of the type of drug used, seems to be the time at which the drug is administered from the first symptoms of the disease. The best results were obtained when it was $\leq 12 \mathrm{~h}[111,129,145]$. In this situation, the treatment period was shortened by up to 3 days compared to treatment $48 \mathrm{~h}$ after symptom onset. Another important factor seems to be the occurrence of fever. A better clinical response to treatment was observed in patients with fever compared to those without fever. In the case of zanamivir, the difference was 2 days on average (Table 4) [41,111]. The patient's age may also be important, as the time to alleviation of symptoms (TTAS) has been reported to be shorter in children treated with oseltamivir than in adults $[53,67]$.

As shown in Table 3, the use of antiviral drugs in influenza therapy has an effect in terms of shortening the TTAS from 0 to 3 days [41,111]. In the case of baloxavir, the 
difference is a little over $24 \mathrm{~h}$ regardless of the age group and is equivalent to the effectiveness of oseltamivir [142-144]. Furthermore, treatment with peramivir and intravenous zanamivir results in a therapeutic effect with TTAS and time to clinical stability comparable to those of treatment with oseltamivir $[84,124,125]$. This is important due to the possibility of intravenous administration of these drugs in hospitalized patients with severe disease for whom administration of oral oseltamivir may be problematic.

These results, though significant and noticeable due to the improvement in the patient's comfort, do not seem to be satisfactory in achieving the optimal therapeutic benefit. On the other hand, the positive effect of zanamivir and oseltamivir on reducing complications was demonstrated [111,112]. Notably, laninamivir [128], zanamivir [66,78,86], and baloxavir [17,132] are among the drugs showing efficacy against some strains resistant to oseltamivir.

Despite an unsatisfactory treatment effect, the use of the above-described drugs in seasonal and post-exposure prophylaxis seems to be much more effective and amounts to about $80 \%$ efficacy for zanamivir [113-115], 70\% to $90 \%$ for oseltamivir [12,14,53,58,118-120], and $62.8 \%$ for laninamivir. In the case of baloxavir, post-exposure cases occurred in $1.9 \%$ of the group using prophylaxis versus $13.6 \%$ in the placebo group [147]. However, it should be emphasized that vaccination remains the most effective type of flu prevention.

\section{Conclusions}

Treating human flu remains a challenge. The anti-influenza drugs available on the market seem to be insufficient in achieving an optimal therapeutic effect. Baloxavir, which is new on the market, exhibits activity against some oseltamivir-resistant strains and does not differ significantly in terms of safety and effectiveness from known drugs used recently for the treatment of influenza. However, its use in a wider group of society than is currently approved requires further research and is highly recommended. The presence of baloxavir on the market also brings new opportunities for combination therapy using drugs from two different groups in terms of the mechanism of action. No such studies have been performed yet, which indicates a new therapeutic direction.

Author Contributions: M.Ś.—writing—original draft, D.M.M.-G.—writing—review and editing, funding acquisition, E.P.- - visualization. All authors have read and agreed to the published version of the manuscript.

Funding: The research was founded by medical University of Warsaw, statutory grant 1M9/N/2022.

Institutional Review Board Statement: Not applicable.

Informed Consent Statement: Not applicable.

Data Availability Statement: Not applicable.

Conflicts of Interest: Authors declare no conflict of interest.

\section{References}

1. Keilman, L.J. Seasonal Influenza (Flu). Nurs. Clin. N. Am. 2019, 54, 227-243. [CrossRef] [PubMed]

2. WHO. Influenza. Available online: https://www.who.int/teams/health-product-policy-and-standards/standards-andspecifications/vaccines-quality/influenza (accessed on 13 October 2021).

3. WHO. Estimate of Influenza Deaths Due to Respiratory Disease. Available online: https:/ / www.who.int/teams/global-influenzaprogramme/surveillance-and-monitoring/burden-of-disease (accessed on 13 October 2021).

4. Putri, W.C.W.S.; Muscatello, D.J.; Stockwell, M.S.; Newall, A.T. Economic burden of seasonal influenza in the United States. Vaccine 2018, 36, 3960-3966. [CrossRef] [PubMed]

5. Marbus, S.D.; Schweitzer, V.A.; Groeneveld, G.H.; Oosterheert, J.J.; Schneeberger, P.M.; van der Hoek, W.; van Dissel, J.T.; van Gageldonk-Lafeber, A.B.; Mangen, M.-J. Incidence and costs of hospitalized adult influenza patients in The Netherlands: A retrospective observational study. Eur. J. Health Econ. 2020, 21, 775-785. [CrossRef] [PubMed]

6. WHO. Seasonal Influenza. Available online: https://www.who.int/health-topics/influenza-seasonal\#tab=tab_1 (accessed on 13 October 2021).

7. Shirley, M. Baloxavir Marboxil: A Review in Acute Uncomplicated Influenza. Drugs 2020, 80, 1109-1118. [CrossRef]

8. Dharmapalan, D. Influenza. Indian J. Pediatrics 2020, 87, 828-832. [CrossRef] 
9. McNicholl, I.R.; McNicholl, J.J. Neuraminidase Inhibitors: Zanamivir and Oseltamivir. Ann. Pharmacother. 2001, 35, 57-70. [CrossRef]

10. Bouvier, N.M.; Palese, P. The biology of Influenza viruses. Vaccine 2008, 265, 49-53. [CrossRef]

11. FDA-41st Edition-2021-Approved Drug Product List. Prescription Drug Product List. pp. 329-457. Available online: https:/ / thefdalawblog.com/wp-content/uploads/2021/01/Orange-Book-41st-Annual.pdf (accessed on 13 October 2021).

12. Gubareva, L.V.; Kaiser, L.; Hayden, F.G. Influenza virus neuraminidase inhibitors. Lancet 2000, 355, 827-835. [CrossRef]

13. Kim, J.-H.; Resende, R.; Wennekes, T.; Chen, H.-M.; Bance, N.; Buchini, S.; Watts, A.G.; Pilling, P.; Streltsov, V.A.; Petric, M.; et al. Mechanism-Based Covalent Neuraminidase Inhibitors with Broad-Spectrum Influenza Antiviral Activity. Science 2013, 340, 71-75. [CrossRef]

14. Moscona, A. Neuraminidase Inhibitors for Influenza. N. Engl. J. Med. 2005, 353, 1363-1373. [CrossRef]

15. Samji, T. Influenza A: Understanding the Viral Life Cycle. Yale J. Biol. Med. 2009, 82, 153-159.

16. Dreitlein, W.B.; Maratos, J.; Brocavich, J. Zanamivir and oseltamivir: Two new options for the treatment and prevention of influenza. Clin. Ther. 2001, 23, 327-355. [CrossRef]

17. O'Hanlon, R.; Shaw, M.L. Baloxavir marboxil: The new influenza drug on the market. Curr. Opin. Virol. 2019, 35, 14-18. [CrossRef]

18. Laborda, P.; Wang, S.-Y.; Voglmeir, J. Influenza Neuraminidase Inhibitors: Synthetic Approaches, Derivatives and Biological Activity. Molecules 2016, 21, 1513. [CrossRef]

19. Dou, D.; Revol, R.; Östbye, H.; Wang, H.; Daniels, R. Influenza A Virus Cell Entry, Replication, Virion Assembly and Movement. Front. Immunol. 2018, 9. [CrossRef]

20. Hubert, T.J.; Dietrich, D.E.; Emrich, H.M. Possible use of Amantadine in depression. Pharmacopsychiatry 1999, 32, 47-55. [CrossRef]

21. Tokimatsu, I.; Nasu, N. Anti-influenza A viral drug-amantadine. Nihon Rinsho 2000, 58, 2288-2292.

22. Yi, M.; Cross, T.A.; Zhou, H.X. A Secondary Gate as a Mechanism for Inhibition of the M2 Proton Channel by Amantadine. J. Phys. Chem. B 2008, 112, 7977-7979. [CrossRef]

23. Balannik, V.; Wang, J.; Ohigashi, Y.; Jing, X.; Magavern, E.; Lamb, R.A.; Degrado, W.F.; Pinto, L.H. Design and Pharmacological Characterization of Inhibitors of Amantadine-Resistant Mutants of the M2 Ion Channel of Influenza A Virus. Biochemistry 2009, 48, 11872-11882. [CrossRef]

24. Danielczyk, W. Twenty-five years of amantadine therapy in Parkinson's disease. J. Neural Transm. Suppl. 1995, 46, 399-405.

25. Horadam, V.W.; Sharp, J.G.; Smilack, J.D.; McAnalley, B.H.; Garriott, J.C.; Stephens, M.K.; Prati, R.C.; Brater, D.C. Pharmacokinetics of Amantadine Hydrochloride in Subjects with Normal and Impaired Renal Function. Ann. Intern. Med. 1981, 94, 454-458. [CrossRef]

26. Roin, S.; Winters, S. Amantadine Hydrochloride: Current and News Uses. J. Neurosci. Nurs. 1990, 22, 322-325. [CrossRef]

27. Dong, G.; Peng, C.; Luo, J.; Wang, C.; Han, L.; Wu, B.; Ji, G.; He, H. Adamantane-resistant influenza a viruses in the world (1902-2013): Frequency and distribution of M2 gene mutations. PLoS ONE 2015, 10, e0119115. [CrossRef]

28. Jefferson, T.; Demicheli, V.; Di Pietrantonj, C.; Rivetti, D. Amantadine and rimantadine for influenza A in adults. Cochrane Database Syst. Rev. 2006, CD001169. [CrossRef]

29. Danysz, W.; Parsons, C.G.; Kornhuber, J.; Schmidt, W.J.; Quack, G. Aminoadamantanes as NMDA receptor antagonists and antiparkinsonian agents-Preclinical studies. Neurosci. Biobehav. Rev. 1997, 21, 455-468. [CrossRef]

30. Müller, T.; Kuhn, W.; Möhr, J.-D. Evaluating ADS5102 (amantadine) for the treatment of Parkinson's disease patients with dyskinesia. Expert Opin. Pharmacother. 2019, 20, 1181-1187. [CrossRef]

31. Hauser, R.A.; Pahwa, R.; Wargi, W.A.; Souza-Prien, C.J.; McClure, N.; Johnson, R.; Nguyen, J.T.; Patni, R.; Went, G.T. Pharmacokinetics of ADS-5102 (Amantadine) Extended Release Capsules Administered Once Daily at Bedtime for the Treatment of Dyskinesia. Clin Pharmacokinet. 2019, 58, 77-88. [CrossRef]

32. Loggini, A.; Tangonan, R.; Ammar, F.E.; Mansour, A.; Goldenberg, F.D.; Kramer, C.L.; Lazaridis, C. The role of amantadine in cognitive recovery early after traumatic brain injury: A systematic review. Clin. Neurol. Neurosurg. 2020, 194, 1-6. [CrossRef]

33. Carabenciov, I.D.; Bureau, B.L.; Cutrer, M.; Savica, R. Amantadine Use for Postconcussion Syndrome. Mayo Clin. Proc. 2019, 94, 275-277. [CrossRef]

34. Nourbakhsh, B.; Revirajan, N.; Morris, B.; Cordano, C.; Creasman, J.; Manguinao, M.; Krysko, K.; Rutatangwa, A.; Auvray, C.; Aljarallah, S.; et al. Safety and efficacy of amantadine, modafinil, and methylphenidate for fatigue in multiple sclerosis: A randomised, placebo-controlled, crossover, double-blind trial. Lancet Neurol. 2020, 20, 38-48. [CrossRef]

35. Rejdak, K.; Grieb, P. Adamantanes might be protective from COVID-19 in patients with neurological diseases: Multiple sclerosis, parkinsonism and cognitive impairment. Mult. Scler. Relat. Disorders Elsevier 2020, 42, 102163. [CrossRef] [PubMed]

36. Aranda-Abreu, G.E.; Aranda-Martinez, J.D.; Araújo, R.; Hernandez-Aguilar, M.E.; Herrera-Covarrubias, D.; Rojas-Durán, F. Observational study of people infected with SARS-CoV-2, treated with amantadine. Pharmacol. Rep. 2020, 72, $1538-1541$. [CrossRef] [PubMed]

37. Bassetti, M.; Castaldo, N.; Carnelutti, A. Neuraminidase inhibitors as a strategy for influenza treatment: Pros, cons and future perspectives. Expert Opin. Pharmacother. 2019, 1465-6566, 1-8. [CrossRef] [PubMed]

38. Lackenby, A.; Besselaar, T.G.; Daniels, R.S.; Fry, A.; Gregory, V.; Gubareva, L.V.; Huang, W.; Hurt, A.C.; Leang, S.-K.; Lee, R.T.C.; et al. Global update on the susceptibility of human influenza viruses to neuraminidase inhibitors and status of novel antivirals, 2016-2017. Antivir. Res. 2018, 157, 38-46. [CrossRef]

39. Gaitonde, D.Y.; Moore, F.C.; Morgan, M.K. Influenza: Diagnosis and Treatment. Am. Fam. Physician 2019, 100, 751-758. 
40. Rech, M.A. Oseltamivir for All: Should It Become an Over-the-Counter Medication for Influenza Treatment? Pharmacother. J. Hum. Pharmacol. Drug Ther. 2020, 40, 182-185. [CrossRef]

41. Hayden, F.G.; Osterhaus, A.D.M.E.; Treanor, J.J.; Fleming, D.M.; Aoki, F.Y.; Nicholson, K.G.; Bohnen, A.M.; Hirst, H.M.; Kenee, O.; Wightman, K. Efficacy and Safety of the Neuraminidase Inhibitor Zanamivir in the Treatment of Influenzavirus Infections. $N$. Engl. J. Med. 1997, 337, 874-880. [CrossRef]

42. Kim, C.U.; Lew, W.; Williams, M.A.; Liu, H.; Zhang, L.; Swaminathan, S.; Bischofberger, N.; Chen, M.S.; Mendel, D.B.; Tai, C.Y.; et al. Influenza neuraminidase inhibitors possessing a novel hydrophobic interaction in the enzyme active site: Design, synthesis and structural analysis of carbocyclic sialic acid analogues with potent anti-influenza activity. J. Am. Chem. Soc. 1997, 119, 681-690. [CrossRef]

43. EMA. Dectova, Summary of Product Characteristics. Available online: https://www.ema.europa.eu/en/documents/productinformation/dectova-epar-product-information_en.pdf (accessed on 13 October 2021).

44. Katzen, J.; Kohn, R.; Houk, J.L.; Ison, M.G. Early oseltamivir after hospital admission is associated with shortened hospitalization: A five-year analysis of oseltamivir timing and clinical outcomes. Clin. Infect. Dis. 2018, 69, 52-58. [CrossRef]

45. Lee, N.; Choi, K.W.; Chan, P.K.; Hui, D.S.C.; Lui, G.C.Y.; Wong, B.C.K.; Wong, R.Y.K.; Sin, W.Y.; Hui, W.M.; Ngai, K.L.K.; et al. Outcomes of adults hospitalised with severe influenza. BMJ J. Thorax. 2010, 65, 510-515. [CrossRef]

46. Louie, J.K.; Yang, S.; Acosta, M.; Yen, C.; Samuel, M.C.; Schechter, R.; Guevara, H.; Uyeki, T.M. Treatment with neuraminidase inhibitors for critically ill patients with influenza A (H1N1)pdm09. Clin. Infect. Dis. 2012, 55, 1198-1204. [CrossRef]

47. Doll, M.K.; Winters, N.; Boikos, C.; Kraicer-Melamed, H.; Gore, G.; Quach, C. Safety and effectiveness of neuraminidase inhibitors for influenza treatment, prophylaxis, and outbreak control: A systematic review of systematic reviews and/or meta-analyses. J. Antimicrob. Chemother. 2017, 72, 2990-3007. [CrossRef]

48. Muthuri, S.G.; Venkatesan, S.; Myles, P.R.; Leonardi-Bee, J.; Al Khuwaitir, T.S.A.; Al Mamun, A.; Anovadiya, A.P.; AzzizBaumgartner, E.; Báez, C.; Bassetti, M.; et al. Effectiveness of neuraminidase inhibitors in reducing mortality in patients admitted to hospital with influenza A H1N1pdm09 virus infection: A meta-analysis of individual participant data. Lancet Respir. Med. 2014, 2, 395-404. [CrossRef]

49. Chow, E.J.; Doyle, J.D.; Uyeki, T.M. Influenza virus-related critical illness: Prevention, diagnosis, treatment. Crit. Care 2019, 23, 214. [CrossRef]

50. Hiba, V.; Chowers, M.; Levi-Vinograd, I.; Rubinovitch, B.; Leibovici, L.; Paul, M. Benefit of early treatment with oseltamivir in hospitalized patients with documented 2009 influenza A (H1N1): Retrospective cohort study. J. Antimicrob. Chemother. 2011, 66, 1150-1155. [CrossRef]

51. Hsu, J.; Santesso, N.; Mustafa, R.; Brozek, J.; Chen, Y.L.; Hopkins, J.P.; Cheung, A.; Hovhannisyan, G.; Ivanova, L.; Flottorp, S.A.; et al. Antivirals for treatment of influenza: A systematic review and meta-analysis of observational studies. Ann. Intern. Med. 2012, 156, 512-524. [CrossRef]

52. Muthuri, S.G.; Myles, P.R.; Venkatesan, S.; Leonardi-Bee, J.; Nguyen-Van-Tam, J.S. Impact of neuraminidase inhibitor treatment on outcomes of public health importance during the 2009-2010 influenza a(H1N1) pandemic: A systematic review and meta-analysis in hospitalized patients. J. Infect. Dis. 2013, 207, 553-563. [CrossRef]

53. Heneghan, C.J.; Onakpoya, I.; Jones, M.A.; Doshi, P.; Del Mar, C.B.; Hama, R.; Thompson, M.J.; Spencer, E.A.; Mahtani, K.R.; Nunan, D.; et al. Neuraminidase inhibitors for influenza: A systematic review and meta-analysis of regulatory and mortality data. Health Technol. Assess. 2016, 42, 5-96. [CrossRef]

54. Kumar, S.; Goicoechea, S.; Kumar, S.; Pearce, C.M.; Durvasula, R.; Kempaiah, P.; Poonam, B.R. Oseltamivir analogs with potent anti-influenza virus activity. Drug Discov. Today. 2020, 25, 1389-1402. [CrossRef]

55. Shtyrya, Y.A.; Mochalova, L.V.; Bovin, N.V. Influenza virus neuraminidase: Structure and function. Acta Naturae. 2009, 1, 26-32. [CrossRef]

56. Gubareva, L.V.; Webster, R.G.; Hayden, F.G. Comparison of the Activities of Zanamivir, Oseltamivir, and RWJ-270201 against Clinical Isolates of Influenza Virus and Neuraminidase Inhibitor-Resistant Variants. Antimicrob. Agents Chemother. 2021, 45, 3403-3408. [CrossRef]

57. Yin, X.; Jiang, N.; Shi, W.; Chi, X.; Liu, S.; Chen, J.-L.; Wang, S. Development and Effects of Influenza Antiviral Drugs. Molecules 2021, 26, 810. [CrossRef]

58. Esposito, S.; Principi, N. Oseltamivir for influenza infection in children: Risks and benefits. Expert Rev. Respir. Med. 2015, 10, 79-87. [CrossRef]

59. Sur, M.; Lopez, M.J.; Baker, M.B. Oseltamivir. 2020. Available online: https://www-1ncbi-1nlm-1nih-1gov-100001atj0c66.han3 .wum.edu.pl/books/NBK539909/ (accessed on 13 October 2021).

60. EMA. List of Nationally Authorised Medicinal Products. 2017. Available online: https://www.ema.europa.eu/en/documents/ psusa/zanamivir-list-nationally-authorised-medicinal-products-psusa/00003141/201701_en.pdf (accessed on 13 October 2021).

61. FDA. Highlights of Prescribing Information. Relenza. Available online: https://www.accessdata.fda.gov/drugsatfda_docs/ label/2010/021036s025lbl.pdf (accessed on 13 October 2021).

62. Australia's National Science Agency. Relenza-The First Effective Flu-Fighter. Available online: https://www.csiro.au/en/ research/health-medical/vaccines/relenza (accessed on 13 October 2021).

63. EMA. Dectova, Authorisation Details. Available online: https://www.ema.europa.eu/en/medicines/human/EPAR/dectova (accessed on 13 October 2021). 
64. EMC. Relenza. Available online: https://www.medicines.org.uk/emc/product/3809/smpc (accessed on 13 October 2021).

65. EMC. Dectova. Available online: https://www.medicines.org.uk/emc/product/10193/smpc (accessed on 13 October 2021).

66. EMA. Dectova, Assessment Report. Available online: https://www.ema.europa.eu/en/documents/assessment-report/dectovaepar-public-assessment-report_en.pdf (accessed on 13 October 2021).

67. EMA; Tamiflu. Summary of Product Characteristic. Available online: https://www.ema.europa.eu/en/documents/productinformation/tamiflu-epar-product-information_en.pdf (accessed on 13 October 2021).

68. FDA; Tamiflu. Highlights of Prescribing Information. Available online: https://www.accessdata.fda.gov/drugsatfda_docs/ label/2016/021087s068,021246s051lbl.pdf (accessed on 13 October 2021).

69. EMC. Tamiflu. Available online: https://www.medicines.org.uk/emc/medicine/20294\#gref (accessed on 13 October 2021).

70. Bardsley-Elliot, A.; Noble, S. Oseltamivir. Drugs 1999, 58, 851-860. [CrossRef]

71. McLaughlin, M.M.; Skoglund, E.W.; Ison, M.G. Peramivir: An intravenous neuraminidase inhibitor. Expert Opin. Pharmacother. 2015, 16, 1889-9000. [CrossRef]

72. Scott, L.J. Peramivir: A Review in Uncomplicated Influenza. Drugs 2018, 78, 1363-1370. [CrossRef]

73. FDA. Rapivab, Prescribing Information. Available online: https://www.accessdata.fda.gov/drugsatfda_docs/label/2014/20642 6lbl.pdf (accessed on 13 October 2021).

74. Shetty, A.K.; Peek, L.A. Peramivir for the treatment of influenza. Expert Rev. Anti-Infect. Ther. 2012, 10, 123-143. [CrossRef]

75. Kashiwagi, S.; Yoshida, S.; Yamaguchi, H.; Niwa, S.; Mitsui, N.; Tanigawa, M.; Yamaguchi, F. Safety of the long-acting neuraminidase inhibitor laninamivir octanoate hydrate in post-marketing surveillance. Int. J. Antimicrob. Agents 2012, 40, 381-388. [CrossRef]

76. ClinicalTrials.gov. Efficacy and Safety Study of Laninamivir Octanoate TwinCaps®Dry Powder Inhaler in Adults with Influenza (Igloo). Available online: https:// clinicaltrials.gov/ct2/show/results/NCT01793883?view=results (accessed on 7 February 2022).

77. Cass, L.M.R.; Efthymiopoulos, C.; Bye, A. Pharmacokinetics of Zanamivir After Intravenous, Oral, Inhaled or Intranasal Administration to Healthy Volunteers. Clin Pharmacokinet. 1999, 36, 1-11. [CrossRef]

78. Weller, S.; Jones, L.S.; Lou, Y.; Peppercorn, A.; Ng-Cashin, J. Pharmacokinetics of Zanamivir following Intravenous Administration to Subjects with and without Renal Impairment. Antimicrob. Agents Chemother. 2013, 57, 2967-2971. [CrossRef] [PubMed]

79. MacConnachie, A.M. Zanamivir (Relenza $\left.{ }^{\circledR}\right)$-A new treatment for influenza. Intensive Crit. Care Nurs. 1999, 15, 369-370. [CrossRef]

80. Marty, F.M.; Man, C.Y.; Horst, C.; Francois, B.; Garot, D.; Máňez, R.; Thamlikitkul, V.; Lorente, J.A.; Álvarez-Lerma, F.; Brealey, D.; et al. Safety and Pharmacokinetics of Intravenous Zanamivir Treatment in Hospitalized Adults with Influenza: An Open-label, Multicenter, Single-Arm, Phase II Study. J. Infect. Dis. 2014, 209, 542-550. [CrossRef] [PubMed]

81. EMA. Dectova (zanamivir) An overview of Dectova and Why It Is Authorised in the EU. Available online: https://www.ema. europa.eu/en/documents / overview / dectova-epar-medicine-overview_en.pdf (accessed on 13 October 2021).

82. Slain, D. Intravenous Zanamivir: A Viable Option for Critically Ill Patients with Influenza. Ann. Pharmacother. 2020, 55, 760-771. [CrossRef] [PubMed]

83. Torti, C.; Mazzitelli, M.; Longhini, F.; Garofalo, E.; Bruni, A.; Giancotti, A.; Barreca, G.S.; Quirino, A.; Liberto, M.C.; Serapide, F.; et al. Clinical outcomes of patients treated with intravenous zanamivir for severe influenza $\mathrm{A}(\mathrm{H} 1 \mathrm{N1}) \mathrm{pdm} 09$ infection: A case report series. BMC Infect. Dis. 2019, 19, 858. [CrossRef]

84. Marty, F.M.; Vidal-Puigserver, J.; Clark, C.; Gupta, S.K.; Merino, E.; Garot, D.; Chapman, M.J.; Jacobs, F.; Rodriguez-Noriega, E.; Husa, P.; et al. Intravenous zanamivir or oral oseltamivir for hospitalised patients with influenza: An international, randomised, double-blind, double-dummy, phase 3 trial. Lancet Respir. Med. 2017, 5, 135-146. [CrossRef]

85. Wijaya, L.; Chua, Y.Y.; Cui, L.; Chan, K.; Tan, B.H. Intravenous zanamivir in critically ill patients due to pandemic 2009 (H I N I) influenza A virus. Singap. Med. 2011, 52, 481.

86. Bradley, J.S.; Blumer, J.L.; Romero, J.R.; Michaels, M.G.; Munoz, F.M.; Kimberlin, D.W.; Pahud, B.; DeBiasi, R.L.; Yamamoto, G.; Roberts, G.; et al. Intravenous Zanamivir in Hospitalized Patients with Influenza. Pediatrics 2017, 140, 2016-2727. [CrossRef]

87. Louie, J.K.; Lampiris, H. Treating Influenza with Neuraminidase Inhibitors. JAMA Intern. Med. 2015, 175, 1-9. [CrossRef]

88. Burnham, A.J.; Baranovich, T.; Govorkova, E.A. Neuraminidase inhibitors for influenza B virus infection: Efficacy and resistance. Antivir. Res. 2013, 100, 520-534. [CrossRef]

89. Davies, B.E. Pharmacokinetics of oseltamivir: An oral antiviral for the treatment and prophylaxis of influenza in diverse populations. J. Antimicrob. Chemother. 2010, 65, ii5-ii10. [CrossRef]

90. Ariano, R.E.; Sitar, D.S.; Zelenitsky, S.A.; Zarychanski, R.; Pisipati, A.; Ahern, S.; Kanji, A.; Rello, J.; Kumar, A. Enteric absorption and pharmacokinetics of oseltamivir in critically ill patients with pandemic (H1N1) influenza. Can. Med. Assoc. J. 2010, 182, 357-363. [CrossRef]

91. Eyler, R.F.; Heung, M.; Pleva, M.; Sowinski, K.M.; Park, P.K.; Napolitano, L.M.; Mueller, B.A. Pharmacokinetics of Oseltamivir and Oseltamivir Carboxylate in Critically Ill Patients Receiving Continuous Venovenous Hemodialysis and/or Extracorporeal Membrane Oxygenation. Pharmacother. J. Hum. Pharmacol. Drug Ther. 2012, 32, 1061-1069. [CrossRef]

92. WHO Guidelines for Pharmacological Management of Pandemic Influenza A(H1N1) 2009 and Other Influenza Viruses. Available online: https:/ / www.who.int/csr/resources/publications/swineflu/h1n1_guidelines_pharmaceutical_mngt.pdf (accessed on 13 October 2021). 
93. He, G.; Massarella, J.; Ward, P. Clinical Pharmacokinetics of the Prodrug Oseltamivir and its Active Metabolite Ro 64-0802. Clin. Pharmacokinet. 1999, 37, 471-484. [CrossRef]

94. Cies, J.J.; Moore, W.S.; Enache, A.; Chopra, A. Peramivir for Influenza A and B Viral Infections: A Pharmacokinetic Case Series. Pharmacother. J. Hum. Pharmacol. Drug Ther. 2019, 39, 1060-1065. [CrossRef]

95. EMA. Ebilfumin. Authorisation Details. Available online: https://www.ema.europa.eu/en/medicines/human/EPAR/ebilfumin\# authorisation-details-section (accessed on 13 October 2021).

96. Okamoto, E. Is oseltamivir (Tamiflu $\left.{ }^{\circledR}\right)$ safe? Re-examining the Tamiflu "ado" from Japan. Expert Rev. Pharm. Outcomes Res. 2010, 10, 17-24. [CrossRef]

97. FDA-Approved Drugs. Available online: https://www.accessdata.fda.gov/scripts/cder/daf/index.cfm?event=BasicSearch process (accessed on 13 October 2021).

98. Drugs.com. Tamiflu Alternatives Compared. Available online: https://www.drugs.com/compare/tamiflu (accessed on 13 October 2021).

99. EMA. Alpivab, Withdrawal Marketing Authorisation in the European Union. Available online: https://www.ema.europa.eu/en/ documents/public-statement/public-statement-alpivab-withdrawal-marketing-authorisation-european-union_en.pdf (accessed on 13 October 2021).

100. Saisho, Y.; Ishibashi, T.; Fukuyama, H.; Fukase, H.; Shimada, J. Pharmacokinetics and safety of intravenous peramivir, neuraminidase inhibitor of influenza virus, in healthy Japanese subjects. Antivir. Ther. 2016, 22, 313-323. [CrossRef]

101. Elsevier; Peramivir. Published 4 February 2021. Available online: https:/ / elsevier.health/en-US/ preview/peramivir (accessed on 7 February 2022).

102. DaiichiSankyo. Approval for the Use of Inavir®to Prevent Influenza. Available online: https://www.daiichisankyo.com/files/ news / pressrelease/pdf/006052/20131220_484_E.pdf (accessed on 13 October 2021).

103. Ikematsu, H.; Kawai, N. Laninamivir octanoate: A new long-acting neuraminidase inhibitor for the treatment of influenza. Expert Rev. Anti-Infect. Ther. 2011, 9, 851-857. [CrossRef]

104. Inavir-Drug Information Sheet. Available online: http:/ /k-tosaka.sakura.ne.jp/FLU/inavir-shiori-Eng.pdf (accessed on 13 October 2021).

105. Ishizuka, H.; Yoshiba, S.; Okabe, H.; Yoshihara, K. Clinical Pharmacokinetics of Laninamivir, a Novel Long-Acting Neuraminidase Inhibitor, After Single and Multiple Inhaled Doses of Its Prodrug, CS-8958, in Healthy Male Volunteers. J. Clin. Pharmacol. 2010, 50, 1319-1329. [CrossRef]

106. Toyama, K.; Furuie, H.; Ishizuka, H. Intrapulmonary Pharmacokinetics of Laninamivir, a Neuraminidase Inhibitor, after a Single Nebulized Administration of Laninamivir Octanoate in Healthy Japanese Subjects. Antimicrob. Agents Chemother. 2017, 62, 1. [CrossRef]

107. Murasaka, T.; Ikemura, K.; Enokiya, T.; Muraki, Y.; Ikemura, M.; Terada, K.; Iwamoto, T.; Okuda, M. Impact of the number of repeated inhalations and patient characteristics on the residual amount of inhaled laninamivir octanoate hydrate dry powder in pediatric patients with influenza. J. Pharm. Health Care Sci. 2017, 3, 26. [CrossRef]

108. Chen, J.Y.; Wei, S.-K.; Lai, C.C.; Weng, T.-S.; Wang, H.-H. A Meta-Analysis Comparing the Efficacy and Safety of Peramivir with Other Neuraminidase Inhibitors for Influenza Treatment. Medicina 2020, 56, 63. [CrossRef]

109. Ishiguro, N.; Koseki, N.; Kaiho, M.; Ariga, T.; Kikuta, H.; Oba, K.; Togashi, T.; Morita, K.; Inagawa, A.; Okamura, A.; et al. Clinical effectiveness of four neuraminidase inhibitors (oseltamivir, zanamivir, laninamivir, and peramivir) for children with influenza A and B in the 2014-2015 to 2016-2017 influenza seasons in Japan. J. Infect. Chemother. 2018, 24, 449-457. [CrossRef]

110. Hata, A.; Akashi-Ueda, R.; Takamatsu, K.; Matsumura, T. Safety and efficacy of peramivir for influenza treatment. Drug Des. Dev. Ther. 2014, 8, 2017-2038. [CrossRef]

111. The MIST (Management of Influenza in the Southern Hemisphere Trialists) Study Group. Randomised trial of efficacy and safety of zanamivir for oral inhalation in treatment of influenza A and B virus infections. Lancet 1998, 12, 1877-1881. [CrossRef]

112. Walker, J.B.; Hussey, E.K.; Treanor, J.J.; Montalvo, A., Jr.; Hayden, F.G. Effects of the Neuraminidase Inhibitor Zanamivir on Otologic Manifestations of Experimental Human Influenza. J. Infect. Dis. 1997, 176, 1417-1422. [CrossRef]

113. Monto, A.S.; Robinson, D.P.; Herlocher, M.L.; Hinson, J.M., Jr.; Elliott, M.J.; Crisp, A. Zanamivir in the Prevention of Influenza Among Healthy Adults. JAMA 1999, 282, 31. [CrossRef]

114. Hayden, F.G.; Gubareva, L.V.; Monto, A.S.; Klein, T.C.; Elliott, M.J.; Hammond, J.M.; Sharp, S.J.; Ossi, M.J. Zanamivir for oral inhalation for the Prevention of Influenza in Families. N. Engl. J. Med. 2000, 343, 1282-1289. [CrossRef]

115. Monto, A.S.; Pichichero, M.E.; Blanckenberg, S.J.; Ruuskanen, O.; Cooper, C.; Fleming, D.M.; Kerr, C. Zanamivir Prophylaxis: An Effective Strategy for the Prevention of Influenza Types A and B within Households. J. Infect. Dis. 2002, 186, 1582-1588. [CrossRef]

116. Treanor, J.J.; Hayden, F.G.; Vrooman, P.S.; Barbarash, R.; Bettis, R.; Riff, D.; Singh, S.; Kinnersley, N.; Ward, P.; Mills, R.G. Efficacy and safety of the oral neuraminidase inhibitor oseltamivir in treating acute influenza: A randomized controlled trial. US oral neuraminidase study group. JAMA 2000, 283, 1016-1024. [CrossRef]

117. Whitley, R.J.; Hayden, F.G.; Reisinger, K.S.; Young, N.; Dutkowski, R.; Ipe, D.; Mills, R.G.; Ward, P. Oral oseltamivir treatment of influenza in children. Pediatric Infect. Dis. J. 2001, 20, 127-133. [CrossRef]

118. Hayden, F.G.; Atmar, R.L.; Schilling, M.; Johnson, C.; Poretz, D.; Paar, D.; Huson, L.; Ward, P.; Mills, R.G. Use of the selective oral neuraminidase inhibitor oseltamivir to prevent influenza. N. Engl. J. Med. 1999, 341, 1336-1343. [CrossRef] [PubMed] 
119. Hayden, F.G.; Belshe, R.; Villanueva, C.; Lanno, R.; Hughes, C.; Small, I.; Dutkowski, R.; Ward, P.; Carr, J. Management of influenza in households: A prospective, randomized comparison of oseltamivir treatment with or without postexposure prophylaxis. $J$. Infect. Dis. 2004, 189, 440-449. [CrossRef] [PubMed]

120. Welliver, R.; Monto, A.S.; Carewicz, O.; Schatteman, E.; Hassman, M.; Hedrick, J.; Jackson, H.C.; Huson, L.; Ward, P.; Oxford, J.S. Effectiveness of oseltamivir in preventing influenza in household contacts: A randomized controlled trial. JAMA 2001, 285, 748-754. [CrossRef] [PubMed]

121. Duval, X.; van der Werf, S.; Blanchon, T.; Mosnier, A.; Bouscambert-Duchamp, M.; Tibi, A.; Enouf, V.; Charlois-Ou, C.; Vincent, C.; Andreoletti, L.; et al. Efficacy of Oseltamivir-Zanamivir Combination Compared to Each Monotherapy for Seasonal Influenza: A Randomized Placebo-Controlled Trial. PLoS Med. 2010, 7, e1000362. [CrossRef]

122. Escuret, V.; Cornu, C.; Boutitie, F.; Enouf, V.; Mosnier, A.; Bouscambert-Duchamp, M.; Gaillard, S.; Duval, X.; Blanchon, T.; Leport, C. Oseltamivir-zanamivir bitherapy compared to oseltamivir monotherapy in the treatment of pandemic 2009 influenza A(H1N1) virus infections. Antivir. Res. 2012, 96, 130-137. [CrossRef]

123. Kohno, S.; Kida, H.; Mizuguchi, M.; Shimada, J. Efficacy and Safety of Intravenous Peramivir for Treatment of Seasonal Influenza Virus Infection. Antimicrob. Agents Chemother. 2010, 54, 4568-4574. [CrossRef]

124. Kohno, S.; Yen, M.-Y.; Cheong, H.-J.; Hirotsu, N.; Ishida, T.; Kadota, J.; Mizuguchi, M.; Kida, H.; Shimada, J. Phase III Randomized, Double-Blind Study Comparing Single-Dose Intravenous Peramivir with Oral Oseltamivir in Patients with Seasonal Influenza Virus Infection. Antimicrob. Agents Chemother. 2011, 55, 5267-5276. [CrossRef]

125. Ison, M.G.; Hui, D.S.; Clezy, K.; O’Neil, B.J.; Flynt, A.; Collis, P.J.; Simon, T.J.; Alexander, W.J. A clinical trial of intravenous peramivir compared with oral oseltamivir for the treatment of seasonal influenza in hospitalized adults. Antivir. Ther. 2012, 18, 651-661. [CrossRef]

126. Shobugawa, Y.; Saito, R.; Sato, I.; Kawashima, T.; Dapat, C.; Dapat, I.C.; Kondo, H.; Saito, K.; Kondo, H.; Suzuki, Y.; et al. Clinical effectiveness of neuraminidase inhibitors-Oseltamivir, zanamivir, laninamivir, and peramivir-For treatment of influenza $\mathrm{A}(\mathrm{H} 3 \mathrm{~N} 2)$ and $\mathrm{A}(\mathrm{H} 1 \mathrm{N1}) \mathrm{pdm} 09$ infection: An observational study in the 2010-2011 influenza season in Japan. J. Infect. Chemother. 2012, 18, 858-864. [CrossRef]

127. Hikita, T.; Hikita, H.; Hikita, F.; Hikita, N.; Hikita, S. Clinical Effectiveness of Peramivir in Comparison with Other Neuraminidase Inhibitors in Pediatric Influenza Patients. Int. J. Pediatrics 2012, 2012, 834181. [CrossRef]

128. Watanabe, A.; Chang, S.; Kim, M.J.; Chu, D.W.; Ohashi, Y. Long-Acting Neuraminidase Inhibitor Laninamivir Octanoate versus Oseltamivir for Treatment of Influenza: A Double-Blind, Randomized, Noninferiority Clinical Trial. Clin. Infect. Dis. 2010, 51, 1167-1175. [CrossRef]

129. Mawatari, M.; Saito, R.; Hibino, A.; Kondo, H.; Yagami, R.; Odagiri, T.; Tanabe, I.; Shobugawa, Y. Effectiveness of four types of neuraminidase inhibitors approved in Japan for the treatment of influenza. PLoS ONE 2019, 14, e0224683. [CrossRef]

130. Koseki, N.; Kaiho, M.; Kikuta, H.; Oba, K.; Togashi, T.; Ariga, T.; Ishiguro, N. Comparison of the clinical effectiveness of zanamivir and laninamivir octanoate for children with influenza A (H3N2) and B in the 2011-2012 season. Influenza Other Resp. Viruses 2014, 8, 151-158. [CrossRef]

131. Kashiwagi, S.; Watanabe, A.; Ikematsu, H.; Uemori, M.; Awamura, S. Long-acting Neuraminidase Inhibitor Laninamivir Octanoate as Post-exposure Prophylaxis for Influenza. Clin. Infect. Dis. 2016, 63, 330-337. [CrossRef]

132. EMA; Xofluza. Highlights of Prescribing Information. Available online: https://www.accessdata.fda.gov/drugsatfda_docs/ label/2019/210854s001lbl.pdf (accessed on 13 October 2021).

133. EMA; Xofluza. Authorisation Details. Available online: https://www.ema.europa.eu/en/medicines/human/EPAR/xofluza\# assessment-history-section (accessed on 13 October 2021).

134. Hayden, F.G.; Sugaya, N.; Hirotsu, N.; Lee, N.; de Jong, M.D.; Hurt, A.C.; Ishida, T.; Sekino, H.; Yamada, K.; Portsmouth, S. Baloxavir Marboxil for Uncomplicated Influenza in Adults and Adolescents. N. Engl. J. Med. 2018, 379, 913-923. [CrossRef]

135. Fang, Q.; Wang, D. Advanced researches on the inhibition of influenza virus by Favipiravir and Baloxavir. Biosaf. Health. 2020, 2, 64-70. [CrossRef]

136. Omoto, S.; Speranzini, V.; Hashimoto, T.; Noshi, T.; Yamaguchi, H.; Kawai, M.; Uehara, T.; Shishido, T.; Naito, A.; Cusak, S. Characterization of influenza virus variants induced by treatment with the endonuclease inhibitor baloxavir marboxil. Sci. Rep. 2018, 8, 9633. [CrossRef]

137. Koshimichi, H.; Ishibashi, T.; Wajima, T. Population Pharmacokinetics of Baloxavir Marboxil in Japanese Pediatric Influenza Patients. J. Pharm. Sci. 2019, 108, P3112-P3117. [CrossRef]

138. Kim, Y.; Lee, S.; Kim, Y.; Jang, I.-J.; Lee, S.H. Pharmacokinetics and safety of a novel influenza treatment (baloxavir marboxil) in Korean subjects compared with Japanese subjects. Am. Soc. Clin. Pharmacol. Theraputics. 2021, 15, 422-432. [CrossRef]

139. EMA; Xofluza. Summary of Product Characteristics. Available online: https://www.ema.europa.eu/en/documents/productinformation/xofluza-epar-product-information_en.pdf (accessed on 13 October 2021).

140. Baker, J.; Block, S.L.; Matharu, B.; Burleigh Macutkiewicz, L.; Wildum, S.; Dimonaco, S.; Collinson, N.; Clinch, B.; Piedra, P.A. Baloxavir Marboxil Single-dose Treatment in Influenza-infected Children. Pediatric Infect. Dis. J. 2020, 39, 700-705. [CrossRef]

141. Watanabe, A.; Ishida, T.; Hirotsu, N.; Kawaguchi, K.; Ishibashi, T.; Shishido, T.; Uehara, T. Baloxavir marboxil in Japanese patients with seasonal influenza: Dose response and virus type/subtype outcomes from a randomized phase 2 study. Antivir. Res. 2019, 163, 75-81. [CrossRef] 
142. ClinicalTrials.gov. A Study of S-033188 (Baloxavir Marboxil) Compared with Placebo or Oseltamivir in Otherwise Healthy Patients With Influenza (CAPSTONE 1). Available online: https:/ / clinicaltrials.gov/ct2/show / NCT02954354 (accessed on 13 October 2021).

143. ClinicalTrials.gov. Study of S-033188 (Baloxavir Marboxil) Compared With Placebo or Oseltamivir in Patients with Influenza at High Risk of Influenza Complications (CAPSTONE 2). Available online: https:/ / clinicaltrials.gov/ct2/show/results / NCT02949 011 (accessed on 13 October 2021).

144. ClinicalTrials.gov. Study to Assess the Safety, Pharmacokinetics, and Efficacy of Baloxavir Marboxil in Healthy Pediatric Participants with Influenza-Like Symptoms. Available online: https: / clinicaltrials.gov/ct2/show / NCT03629184?term=baloxavir+ Marboxil\&cond=Influenza\&draw $=2 \&$ rank $=3$ (accessed on 13 October 2021).

145. Ison, M.G.; Portsmouth, S.; Yoshida, Y.; Shishido, T.; Mitchener, M.; Tsuchiya, K.; Uehara, T.; Hayden, F.G. Early treatment with baloxavir marboxil in high-risk adolescent and adult outpatients with uncomplicated influenza (CAPSTONE-2): A randomised, placebo-controlled, phase 3 trial. Lancet Infect. Dis. 2020, 20, 1204-1214. [CrossRef]

146. ClinicalTrials.gov. Study to Assess the Safety, Pharmacokinetics, and Efficacy of Baloxavir Marboxil in Healthy Pediatric Participants from Birth to <1 Year with Influenza-like Symptoms. Available online: https://clinicaltrials.gov/ct2/show / NCT036 53364?term=baloxavir+Marboxil\&cond=Influenza\&draw=2\&rank=1 (accessed on 13 October 2021).

147. Ikematsu, H.; Hayden, F.G.; Kawaguchi, K.; Kinoshita, M.; Jong, D.; Lee, N.; Takashima, S.; Noshi, T.; Tsuchiya, K.; Uehara, T. Baloxavir marboxil for prophylaxis against influenza in household contacts. N. Engl. J. Medicine. 2020, 383, 309-320. [CrossRef]

148. Umemura, T.; Mutoh, Y.; Kawamura, T.; Saito, M.; Mizuno, T.; Ota, A.; Kozaki, K.; Yamada, T.; Ikeda, Y.; Ichihara, T. Efficacy of baloxavir marboxil on household transmission of influenza infection. J. Pharm. Health Care Sci. 2020, 6, 1-6. [CrossRef]

149. Liu, T.; Liu, M.; Chen, F.; Chen, F.; Tian, Y.; Huang, Q.; Liu, S.; Yang, J. A small-molecule compound has anti-influenza A virus activity by acting as a "PB2 inhibitor". Mol. Pharm. 2018, 15, 4110-4120. [CrossRef]

150. Yang, F.; Pang, B.; Lai, K.K.; Cheung, N.N.; Dai, J.; Zhang, W.; Zhang, J.; Chan, K.H.; Chen, H.; Sze, K.-H.; et al. Discovery of a Novel Specific Inhibitor Targeting Influenza A Virus Nucleoprotein with Pleiotropic Inhibitory Effects on Various Steps of the Viral Life Cycle. J. Virol. 2021, 95, e01432-20. [CrossRef]

151. Watanabe, T.; Hayashi, K.; Kan, T.; Ohwaki, M.; Kawahara, T. Anti-Influenza virus effects of Enterococcus faecalis KH2 and Lactobacillus plantarum SNK12 RNA. Biosci. Microbiota Food Health 2021, 40, 43-49. [CrossRef]

152. You, H.L.; Chen, C.J.; Eng, H.L.; Liao, P.L.; Huang, S.T. The Effectiveness and Mechanism of Toona sinensis Extract Inhibit Attachment of Pandemic Influenza A (H1N1) Virus. Evid. Based Complement Alternat. Med. 2013, 2013, 479718. [CrossRef] [PubMed]

153. You, H.L.; Huang, C.C.; Chen, C.J.; Chang, C.C.; Liao, P.L.; Huang, S.T. Anti-pandemic influenza A (H1N1) virus potential of catechin and gallic acid. Journal of the Chinese Medical Association. JCMA 2018, 81, 458-468. [CrossRef] [PubMed] 